Review article

\title{
Sources and environmental behaviors of Dechlorane Plus and related compounds - A review
}

\author{
Pu Wang a , Qinghua Zhang a,b,*, Haidong Zhang ${ }^{\mathrm{c}}$, Thanh Wang ${ }^{\mathrm{d}}$, Huizhong Sun ${ }^{\mathrm{a}}$, Shucheng Zheng ${ }^{\mathrm{a}}$, \\ Yingming $\mathrm{Li}^{\mathrm{a}}$, Yong Liang ${ }^{\mathrm{b}}$, Guibin Jiang ${ }^{\mathrm{a}}$ \\ a State Key Laboratory of Environmental Chemistry and Ecotoxicology, Research Center for Eco-Environmental Sciences, Chinese Academy of Sciences, Beijing 100085, China \\ b Institute of Environment and Health, Jianghan University, Wuhan 430056, China \\ ${ }^{c}$ Department of Geography and Environment, Baoji University of Arts and Sciences, Baoji 721013, China \\ ${ }^{\mathrm{d}}$ MTM Research Center, School of Science and Technology, Örebro University, Örebro 70182, Sweden
}

\section{A R T I C L E I N F O}

\section{Article history:}

Received 16 October 2015

Received in revised form 18 December 2015

Accepted 19 December 2015

Available online 4 January 2016

\section{Keywords:}

Dechlorane Plus

Analytical methods

Emission sources

Environmental behaviors

Related compounds

\begin{abstract}
A B S T R A C T
Although Dechlorane Plus (DP) has been used as a polychlorinated flame retardant for almost half a century, its detection in the environment was not reported until 2006. The subsequent intensive research has confirmed its global ubiquity. A few reviews have presented the properties, analytical methods and environmental occurrence of DP and related compounds in the past several years. The present review emphasizes on the environmental behavior of DP isomers which is assessed by the variation of the isomer ratio of DP in various matrices. Other aspects including the analytical methods, emission sources, general environmental occurrence and bioaccumulation of DP are also summarized.

In this review, three typical emission sources in the environment are categorized after introducing the measurement method of DP. The temporal-spatial distribution is then evaluated at the global scale, which provides an integrated representation of the environmental occurrence of DP and potential impact on the human health and ecosystems. The variations of DP isomer ratio in various matrices reinforce its source related distribution and their stereoselective bioaccumulation. Thereafter, DP related compounds and dechlorinated analogs are briefly summarized in regards to their occurrence in various matrices, suggesting their ubiquity in the environment and bioavailability. Further studies are required to better assess the exposures and toxicological effects of DP and its analogs. A special concern is the serious contamination in e-waste recycling areas in developing countries, where long-term monitoring data on the association of DP exposure and adverse effects to human health and ecosystems is urgently needed.
\end{abstract}

(C) 2015 Elsevier Ltd. All rights reserved.

\section{Contents}

1. Introduction

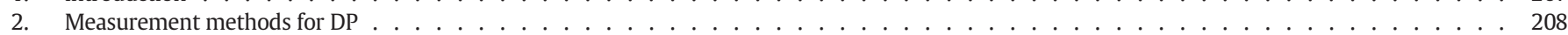

2.1. Sample collection. . . . . . . . . . . . . . . . . . . . . . . . . . . . . . . . . . 208

2.2. Sample extraction and clean-up . . . . . . . . . . . . . . . . . . . . . . . . . . . . . . . . . . . . . . . . 208

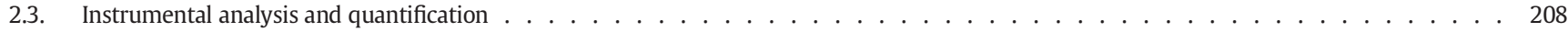

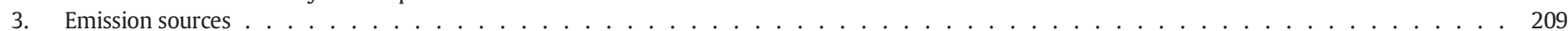

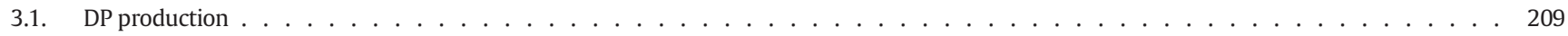

3.2. E-waste dismantling activity . . . . . . . . . . . . . . . . . . . . . . . . . . . . . . . . 209

3.3. Urban/industrial activity . . . . . . . . . . . . . . . . . . . . . . . . . . . . . . . . . . . . . 210

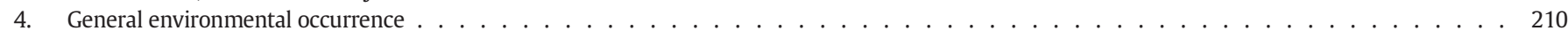

4.1. Global distribution . . . . . . . . . . . . . . . . . . . . . . . . . . . . . . . . . . 210

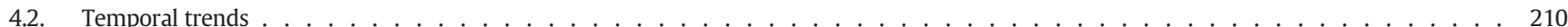

5. Bioaccumulation and biomagnification potential . . . . . . . . . . . . . . . . . . . . . . . 212

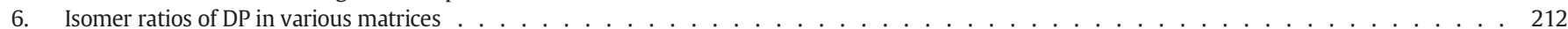

* Corresponding author at: State Key Laboratory of Environmental Chemistry and Ecotoxicology, Research Center for Eco-Environmental Sciences, Chinese Academy of Sciences, Beijing 100085, China.

E-mail address: qhzhang@rcees.ac.cn (Q. Zhang). 
6.1. Commercial products. . . . . . . . . . . . . . . . . . . . . . . . . . . . . . . . . . . . 212

6.2. Atmosphere. . . . . . . . . . . . . . . . . . . . . . . . . . . . . . . . . . 212

6.3. Water. . . . . . . . . . . . . . . . . . . . . . . . . . . . . . . . . . . . . . 213

6.4. Soil, sediment and sewage sludge . . . . . . . . . . . . . . . . . . . . . . . . . . . . . . . . . . . . . 213

6.5. Aquatic biota . . . . . . . . . . . . . . . . . . . . . . . . . . . . . . . . . . . . 214

6.6. Terrestrial organism ... . . . . . . . . . . . . . . . . . . . . . . . . . . . . . . . . . 215

6.7. Human beings . . . . . . . . . . . . . . . . . . . . . . . . . . . . . . . . . . . . . . . . . . 216

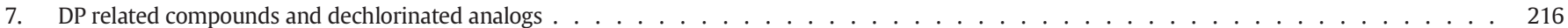

7.1. DP related compounds . . . . . . . . . . . . . . . . . . . . . . . . . . . . . . . . . . . . . . . . 216

7.2. DP dechlorinated analogs . . . . . . . . . . . . . . . . . . . . . . . . . . . . . . . . . . . . . . . 217

8. Conclusions and recommendations. . . . . . . . . . . . . . . . . . . . . . . . . . . . . . . . . . . . . . . . . . 218

Acknowledgement. . . . . . . . . . . . . . . . . . . . . . . . . . . . . . . . . . . . . 218

Appendix A. Supplementary data . . . . . . . . . . . . . . . . . . . . . . . . . . . . . . . . . . . . . . . . . . . . . 218

References . . . . . . . . . . . . . . . . . . . . . . . . . . . . . . . . . . . . 218

\section{Introduction}

Dechlorane Plus (DechPlus or Dechlorane 605, Abbreviation: DP, CAS\# 13560-89-9) is a polychlorinated flame retardant with the chemical formula of $\mathrm{C}_{18} \mathrm{H}_{12} \mathrm{Cl}_{12}$ and a molecular weight of 653.70 . It was developed as a substitute for Dechlorane (also called Mirex) which was commercialized as pesticide and additive flame retardant but banned in the 1970s due to its biological toxicity (Hoh et al., 2006). DP was produced by a Diels-Alder condensation of two equivalents of hexachlorocyclopentadiene with one equivalent of 1,5-cyclooctadiene as shown in Fig. 1. The commercially available formulation of DP contains two stereoisomers, syn-DP (CAS\# 135821-03-3) and anti-DP (CAS\# 135821-74-8), in the approximate ratio of 1:3 (Luo et al., 2013; Sverko et al., 2011a) (Fig. 1). The physicochemical properties of DP are listed in Table 1.

DP was first manufactured by OxyChem (Niagara Falls, NY, USA) and was mainly used as an additive flame retardant in electrical wire and cable coatings, plastic roofing materials, computer connectors and other polymeric systems since the 1960s. It has also been manufactured by Jiangsu Anpon Electrochemical Company located in East China (Huai'an, China) since 2003. Three commercial products of DP are available, DP-25, DP-35 and DP-515, all of which contain the same compound but with different particle sizes. DP is classified as a low production volume chemical in the EU, while it is categorized as a high production volume chemical in the USA. The annual productions were estimated to be 450-4500 tonnes in USA since 1986 (Qiu et al., 2007) and 300-1000 tonnes by Anpon in China since 2003 (Wang et al., 2010a). The global annual production amount approximates 5000 tonnes (Ren et al., 2008).

Although DP has been produced and used for almost half a century, its first environmental detection was only reported in 2006 in the Great Lakes Basin in North America (Hoh et al., 2006). Since then, many studies gradually outlined the environmental occurrence and behavior of DP, as well as its toxic effects. DP was considered to be chemically stable in various environmental compartments, and the half-life was estimated to be over 24 years in water, with minimal or no anaerobic

Table 1

Physicochemical properties of DP.

\begin{tabular}{ll}
\hline Property & Value \\
\hline Melting point & $350{ }^{\circ} \mathrm{C}$ with decomposition \\
Density & $1.8 \mathrm{~g} \mathrm{~cm}^{-3}$ \\
Vapor pressure & $0.006 \mathrm{~mm} \mathrm{Hg}\left(\right.$ at $\left.200{ }^{\circ} \mathrm{C}\right)$ \\
Water solubility & $207 \mathrm{ng} \mathrm{L}^{-1} ; 572 \mathrm{ng} \mathrm{L}^{-1}$ \\
Recommended operating temperature & $285^{\circ} \mathrm{C}($ maximum $)$ \\
Octane-water partition coefficient $\left(\log K_{O W}\right)$ & 9.3 \\
Octane-air partition coefficient $\left(\log K_{O A}\right)$ & 12.26 \\
Sediment-water partition coefficient $\left(\log K_{P}\right)$ & 6.65 \\
\hline
\end{tabular}

Data cited from OxyChem, 2007.

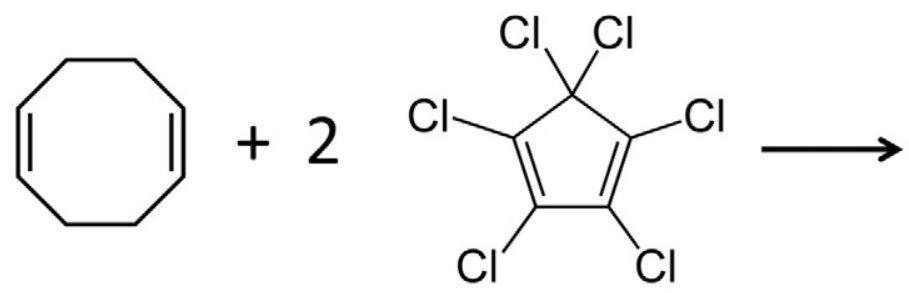

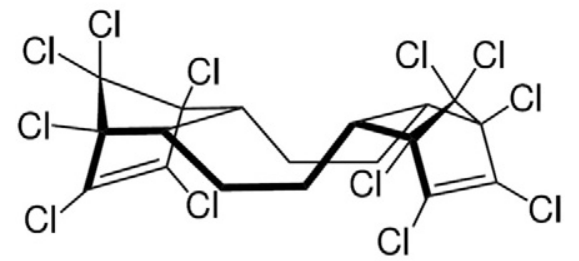

syn-DP

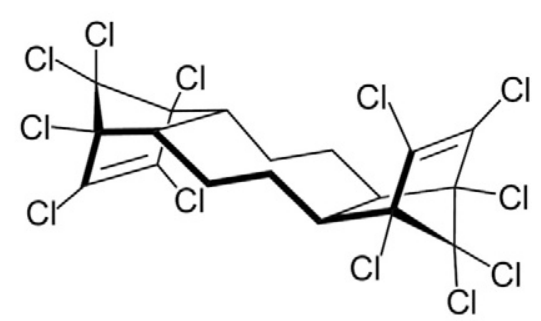

anti-DP

Fig. 1. The two stereoisomers of DP produced from the Diels-Alder condensation of hexachlorocyclopentadiene and 1,5-cyclooctadiene. 
degradation (OxyChem, 2007; Sverko et al., 2011a). It was also found to be persistent in suspended sediment (half-life: approximately 17 years, Sverko et al., 2008) and fish (half-life: 14 years, Ismail et al., 2009). It has been observed in the Arctic regions and marine environment, indicating its long-range atmospheric transport (LRAT) potential (Möller et al., 2010, 2011, 2012a). DP was also found to bioaccumulate and biomagnify in biota (Peng et al., 2014; Tomy et al., 2007, 2008; Wang et al., 2015; Wu et al., 2010). Recently, Toxicological research indicated that oral exposure to DP can induce hepatic oxidative damage and perturbations of metabolism and signal transduction of male mice $\mathrm{CWu}$ et al., 2012). DP was also observed to alert mRNA expression levels of certain enzymes and their activities in liver of Sprague-Dawley rats, although there was no observable effect in histopathology and death ( $\mathrm{Li}$ et al., 2013). Based on the protein responses induced by DP, Liang et al. (2014) suggested that DP may induce apoptosis in the liver of juvenile Chinese sturgeon. These studies provide further concerns on the potential threat of DP to human health and ecosystems.

A few reviews (Feo et al., 2012; Luo et al., 2013; Sverko et al., 2011a; Vorkamp and Rigét, 2014; Xian et al., 2011) have presented the properties, analytical methods and environmental levels of DP and related compounds in the past several years. This review is aimed at summarizing our current understanding of DP in the environment, including analytical methods, emission sources, and the environmental behaviors. DP isomer ratios in various matrices and tissues were specifically summarized to discuss plausible environmental processes and biotransformation of DP in biota and humans. The environmental occurrence of related compounds and dechlorination (or degradation) products of DP were also briefly reviewed. Most of the literatures on DP in the environment and in biota, published up until July 2015, was acquired and classified based on the Web of Science database. The available data on DP concentrations and isomer ratios were given in Tables S1-S7.

\section{Measurement methods for DP}

\subsection{Sample collection}

The environmental sampling strategy and devices used for DP were usually similar to those of persistent organic pollutants (POPs), e.g., polybrominated diphenyl ethers (PBDEs), polychlorinated biphenyls (PCBs), etc. For instance, water was collected in precleaned polyethylene, polypropylene or polycarbonate sampling containers and glass containers (preferably brown), and then stored at $4{ }^{\circ} \mathrm{C}$ until extraction. In some cases, $\mathrm{C} 18, \mathrm{XAD}-2$ and XAD-4 resins were employed for adsorption of the organic matter in water, while glass fiber filter (GFF) was used to collect the particle phase (Möller et al., 2010, 2011, 2012b; Na et al., 2015; Salamova and Hites, 2011; Venier et al., 2014; Wu et al., 2010). Sediment was sampled by stainless spade, grab or core sampler and then stored under $-20{ }^{\circ} \mathrm{C}$ in the laboratory ( $\mathrm{Ma}$ et al., 2011; Zhao et al., 2011; Zhu et al., 2013). Solid samples including biotic matrices were generally freeze-dried, ground and homogenized prior to extraction. We herein emphasized on the air sampling of DP due to some difference between sampling strategies (e.g., sampling rate) for DP and POPs. Due to its high hydrophobicity $\left(\log K_{O W}=9.3\right.$, $\log K_{O A}=12.26$ ) (Feo et al., 2012; OxyChem, 2007; Sverko et al., 2011a), DP is mainly adsorbed to airborne particles (Hoh et al., 2006), and high-volume air samplers were widely utilized to collect DP in the air in both particle-phase and gas-phase. However, as passive air samplers show many advantages to active air samplers, such as no electricity requirement, low cost and simple construction, they have also been used to collect airborne DP (Klánová et al., 2008; Ren et al., 2008; Yu et al., 2015). XAD-2 resin and polyurethane foam (PUF) have been individually used for DP monitoring at a regional and global scale (Baek et al., 2013; Hoh et al., 2006; Ma et al., 2011; Möller et al., 2010, 2011; Peverly et al., 2015; Ren et al., 2008; Sverko et al., 2010a). A low sampling rate, commonly $0.5 \mathrm{~m}^{3} \mathrm{~d}^{-1}$ was recommended for DP relative to POPs substances (3-5 $\mathrm{m}^{3} \mathrm{~d}^{-1}$, Shoeib and Harner, 2002) when using
PUF disk sampling deployment since only the fine/ultrafine fraction can enter the sampling chamber and be collected on the PUF disk (Klánová et al., 2008; Ren et al., 2008; Sverko et al., 2010a). In some cases tree bark was also collected to reflect the distribution of DP in the environment (Qiu and Hites, 2008; Salamova and Hites, 2010). Salamova and Hites (2010) found that the correlation of DP concentrations in tree bark and air particle was significant $\left(\mathrm{r}^{2}=0.818, p=\right.$ 0.035). The correlation between DP precipitation and tree bark concentrations was also significant $\left(r^{2}=0.848, p=0.026\right.$ ) (Salamova and Hites, 2010). These studies indicate that tree bark can effectively scavenge DP from air, and could therefore be a good indicator of levels of DP in the atmosphere.

\subsection{Sample extraction and clean-up}

Soxhlet extraction (SE), liquid-liquid extraction (LLE), solid-phase extraction (SPE) and pressurized liquid extraction (PLE) including accelerated solvent extraction (ASE) could generally be utilized for DP extraction in various samples. SE and PLE (including ASE) were applied to solid samples, while LLE and SPE (e.g., C18) were used for liquid sample extraction (Na et al., 2015). Mixed organic solvents, such as n-hexane/ acetone ( $v / v: 1 / 1)$ (Hoh et al., 2006; Ismail et al., 2009; Peverly et al., 2015; Ren et al., 2008; Salamova et al., 2014; Zhang et al., 2011a, b), n-hexane/dichloromethane ( $v / v: 1 / 1)$ (De la Torre et al., 2011; Möller et al., 2010, 2011; Zhang et al., 2013), and the same mixtures with different proportions (Kang et al., 2010; Tomy et al., 2008; Wu et al., 2010; Xian et al., 2011), were commonly used for extraction.

Cleanup or purification of the environmental sample extracts could be done by a silica gel column (Hoh et al., 2006; Ismail et al., 2009; Ren et al., 2008; Salamova et al., 2014) or a multilayer column packed with acidic and basic silica gel (Jia et al., 2011; Kang et al., 2010; Liu et al., 2014; Wu et al., 2010; Zhang et al., 2013) except for sediment. It was also reported that alumina and Florisil columns, as well as commercial SPE column (i.e., Oasis ${ }$ HLB) were effective (Cequier et al., 2015; Zhang et al., 2011b; Zheng et al., 2015a). Florisil column was also used to separate Dechloranes from hexabromocyclododecane (HBCD) (Ismail et al., 2009), while a column containing 3.5\% ( $w / w)$ water deactivated silica gel could separate DP and brominated flame retardants (BFRs) from organophosphate esters (OPEs) (Salamova et al., 2014). Hexane and hexane/dichloromethane were mainly used for elution of the analytes. For sediment samples, copper powder was commonly added into the sample during or after extraction to remove elemental sulfur (De la Torre et al., 2011; Feo et al., 2012). In addition, gel-permeation chromatography (GPC, Bio-Beads SX-3) was also employed to remove large molecules such as lipid and humus, as well as elemental sulfur in sediment (Davis et al., 2012; Feo et al., 2012). GPC was also widely used to remove lipid and protein in biota samples (Jia et al., 2011; Zhang et al., 2013). In some cases, sulfuric acid or acidic silica gel was alternatively added to the extract to remove lipid in biota prior to column cleanup (Ismail et al., 2009; Qiu and Hites, 2008; Ren et al., 2008). However, if DP mono adduct (DPMA), arising from the Diels-Alder reactions of impurities present in feedstock (1,3- or 1,5cyclooctadiene) (Sverko et al., 2010b), would be analyzed along with DP, nondestructive methods such as GPC were strongly suggested for sample cleanup because acid treatment will degrade DPMA by attacking at its nonhalogenated double bond (Feo et al., 2012; Sverko et al., 2010b).

\subsection{Instrumental analysis and quantification}

Chromatographic separation was usually achieved using capillary gas chromatography (GC) columns with a non-polar stationary phase, such as DB-5MS (De la Torre et al., 2011; Hoh et al., 2006; Jia et al., 2011; Ren et al., 2008; Zeng et al., 2014; Zhang et al., 2013; Zheng et al., 2015a), DB-5HT (Muñoz-Arnanz et al., 2011), DB-XLB (Chen et al., 2013a, 2013b; Mo et al., 2013; Yan et al., 2012; Zhang et al., 
2011b), CP-Sil 13 CB (Zhang et al., 2011a), VF-5MS (Peng et al., 2012, 2014), Rxi-5MS (Qiu and Hites, 2008) and Rtx-1614 (Ben et al., 2013; Li et al., 2014; Peverly et al., 2015). The $15 \mathrm{~m}$ and $30 \mathrm{~m}$ columns were generally selected. GC run time depends on column length, while both syn-DP and anti-DP could be completely separated in a total run time of $35 \mathrm{~min}$. Splitless injection was used at a high temperature, such as $280{ }^{\circ} \mathrm{C}$ and $285^{\circ} \mathrm{C}$, for flash vaporization of the sample but below the thermal degradation temperature of DP (approximately $285^{\circ} \mathrm{C}$ ) (Xian et al., 2011). The GC to mass spectrometry (MS) transfer line was generally held at the similar temperature as the injection port. Different GCMS approaches, including electron capture negative ion (ECNI)-MS, negative chemical ionization (NCI)-MS, NCI-MS/MS and electron impact-high resolution mass spectrometry (EI-HRMS), were generally applied for DP analysis and quantification (Barón et al., 2012, 2014a, 2014b; De la Torre et al., 2010a; Hoh et al., 2006; Kang et al., 2010; Möller et al., 2010; Muñoz-Arnanz et al., 2011; Qiu and Hites, 2008; Xiao et al., 2012; Zeng et al., 2014). Molecular ion fragments at $\mathrm{m} / \mathrm{z}$ 651.8/653.8 were generally selected for DP monitoring in ECNI-MS and NCI-MS, while the selected ion and transition at $654>35 /$ $654>37$ were monitored in NCI-MS/MS (Barón et al., 2012). In order to obtain relatively high intensity of ion response, lower temperatures such as $150^{\circ} \mathrm{C}$ (De la Torre et al., 2010a; Hoh et al., 2006; Möller et al., 2010; Zeng et al., 2014) and $200{ }^{\circ} \mathrm{C}$ (Qiu and Hites, 2008) were recommended in ECNI (or $\mathrm{NCI}$ ) mode. In EI mode, fragmentation process was much more extensive and therefore the two most abundant ions of a fragment cluster (m/z: 271.8102/273.8072) were selected for DP monitoring when using HRMS (Feo et al., 2012; Shen et al., 2011a,b). EI mode was not recommended since an intense ion at m/z $270\left(\mathrm{C}_{5} \mathrm{Cl}_{6}^{+}\right)$ will be formed in retro-Diels-Alder fragmentation, which may make the intensity of molecular ion low or even absent (Feo et al., 2012; Sverko et al., 2010b). Even so, there were many successful measurements conducted by monitoring the 271.8102/273.8072 ions using EI in HRMS (Brasseur et al., 2014; Shen et al., 2010, 2011a, 2011b).

Liquid chromatography-tandem mass spectrometer system (LC$\mathrm{MS} / \mathrm{MS}$ ) with an atmospheric pressure chemical ionization (APCI) interface was also reported to successfully measure halogenated flame retardants including DP in marine mammals (Zhu et al., 2013, 2014). Chromatographic separation was performed on a Zorbax SB-C18 column, and the mobile phase consisted of methanol/water $(85: 15)$ and methanol. The selected ion and transition were $632.6>560.8 /$ $634.6>560.8$ for anti-DP and $632.7>560.8 / 634.7>560.8$ for syn-DP, respectively.

With regard to DP quantification, ${ }^{13} \mathrm{C}$-labeled internal standards used for PBDEs were employed when isotopically labeled Dechloranes were not available, such as ${ }^{13} \mathrm{C}-3,3^{\prime}, 4,4^{\prime}$-tetrabromodiphenyl ether $\left({ }^{13} \mathrm{C}-\mathrm{BDE}-77\right)$ and ${ }^{13} \mathrm{C}-2,2^{\prime}, 4,4^{\prime}, 5,5^{\prime}$-hexabromodiphenyl ether $\left({ }^{13} \mathrm{C}\right.$ BDE-153) (Ren et al., 2009). Some BDE congeners, e.g., BDE-71, -77, -126 and -166 which could not be detected in the environment, were also served as internal standards in some works (Peverly et al., 2015; Ismail et al., 2009). Besides these, ${ }^{13}$ C-PCB-180 and -209 were selected due to their similar chromatographic behaviors to DP (Peng et al., 2012, 2014; Zhang et al., 2013). In recent years, isotopically labeled DP were commercially produced $\left({ }^{13} \mathrm{C}\right.$-syn-DP and ${ }^{13} \mathrm{C}$-anti-DP), making isotopic dilution feasible and pratical for DP determination (Barón et al., 2012; Brasseur et al., 2014; Fang et al., 2014; Huber et al., 2015; Ma et al., 2015; Newton et al., 2015).

The method detection limits (MDLs) for DP were reported at the level of $\mathrm{pg} \mathrm{m}^{-3}$ in air (Ma et al., 2011; Möller et al., 2012a,b; Xiao et al., 2012), pg L ${ }^{-1}$ in water (Ma et al., 2011; Na et al., 2015; Qi et al., 2010; Venier et al., 2014), pg g $^{-1}$ dry weight (dw) in soil and sediment (Barón et al., 2012, 2014a; Ma et al., 2011; Qi et al., 2010; Shen et al., 2011a,b; Wang et al., 2010a,b), and ng g ${ }^{-1}$ lipid weight (lw) in biota samples (Guerra et al., 2011; Peng et al., 2015; Salamova and Hites, 2013; Yan et al., 2012; Zhang et al., 2011a, 2015; Zhu et al., 2014), respectively. Even lower MDL values were obtained in fish $\left(\mathrm{pg} \mathrm{g}^{-1} \mathrm{lw}\right)$ when using GC-NCI-MS/MS and GC-EI-HRMS (Barón et al., 2012; Shen et al., 2010, 2011a), which guaranteed the detection of DP with lower levels in the background areas.

\section{Emission sources}

In general, the flame retardants include additive fire retardants and reactive fire retardants. DP was initially manufactured to replace Mirex and used as an additive flame retardant in industrial and household products. Therefore, DP production and application, as well as their recycling process could lead to DP emission into the environment.

\subsection{DP production}

Considerable numbers of DP monitoring have been carried out in the vicinity of the North American Great Lakes and Huai'an City, China, where the only two DP manufacturers in the world are located. Evidently high levels of DP (sum of the anti- and syn-isomers, the same below) have been generally reported in various matrices from these two areas, indicating an influence by DP production (Tables S1-S7). Air samples collected from the Integrated Atmospheric Deposition Network (IADN) stations located near the Great Lake shores demonstrated that the single highest DP concentration $\left(490 \mathrm{pg} \mathrm{m}^{-3}\right.$ ) occurred at the site nearby Niagara Falls, where OxyChem is situated (Hoh et al., 2006). High average concentration of DP was observed in ambient air from the same sampling point $\left(20 \pm 6 \mathrm{pg} \mathrm{m}^{-3}\right)$ in the following years (Venier and Hites, 2008). High levels of DP were also observed in sediments from Niagara River and Lake Ontario (Hoh et al., 2006; Sverko et al., 2008; Yang et al., 2011). In egg pools (pooled per year per site) of a Great Lakes biomonitoring species (herring gull, Larus argentatus) spanning 1982-2006, a significant negative relationship was observed between DP concentrations and the distance from the DP production facility ( $p<0.001$ ) (Gauthier and Letcher, 2009). Qiu and Hites (2008) also found that the highest DP concentrations in tree barks were $>100 \mathrm{ng} \mathrm{g}^{-1}$ in the city of Niagara Falls, and dropped rapidly with distance from the production site, suggesting that OxyChem in Niagara Falls was the main DP contributor to the surrounding areas. In China, DP concentrations showed the highest levels in various matrices around the DP facility (Anpon) and soil concentrations surrounding the facility decreased by an order of magnitude within $7.5 \mathrm{~km}$ (Wang et al., 2010a; Zheng et al., 2015b). Zhang et al. (2013) assessed the occupational exposure to DP and found that DP concentrations were the highest in the blood and hair of workers in the plant, suggesting an evident occupational exposure of manufacturing workers to DP. All these studies provide solid evidences for elevating DP level in the surrounding environment due to DP production, which could add to increased risk for adverse effects in humans and ecosystems in the vicinity of the production site.

\subsection{E-waste dismantling activity}

Discarded electrical and electronic equipment, often called e-waste, has raised great concern to the environment and human health, particularly in developing countries. Recycling of e-wastes could release particles loaded with heavy metals and flame retardants into the atmosphere and adjacent environmental compartments. In typical ewaste dismantling areas, e.g., Guiyu and Qingyuan in South China, where informal e-waste recycling activity was prevalent several years ago, DP concentration was $3327 \mathrm{ng} \mathrm{g}^{-1} \mathrm{dw}$ in soil from the e-waste recycling site (Yu et al., 2010). The levels fell dramatically with increasing distance away from the site, suggesting an evident influence of ewaste dismantling activities to the surrounding environment (Yu et al., 2010). In a reservoir in the vicinity of e-waste recycling workshops in South China, DP was detected in all the aquatic species (e.g., water snake, mud carp, crucian carp, northern snakehead, prawn and Chinese mysterysnail) with concentrations of 19.1-9630 $\mathrm{ng} \mathrm{g}^{-1} \mathrm{lw}$, which were much higher than those in the reference mud carp (syn-DP: $1.35 \pm$ 
$1.35 \mathrm{ng} \mathrm{g}^{-1} \mathrm{lw}$; anti-DP: $7.41 \pm 7.32 \mathrm{ng} \mathrm{g}^{-1} \mathrm{lw}$ ) (Wu et al., 2010). In common kingfishers (Alcedo atthis) collected from an e-waste dismantling site in the Pearl River Delta, DP levels (29-150 ng g ${ }^{-1}$ lw with a median of $58 \mathrm{ng} \mathrm{g}^{-1} \mathrm{lw}$ ) were one order of magnitude greater than those from the reference site (median: $3.9 \mathrm{ng} \mathrm{g}^{-1} \mathrm{lw}$ ) (Mo et al., 2013). A similar observation was obtained in the prey fishes (six species) with even larger differences between the levels in the e-waste area and the reference site (60-420 $\mathrm{ng} \mathrm{g}^{-1}$ lw versus 0.96$8.8 \mathrm{ng} \mathrm{g}^{-1} \mathrm{lw}$ ) (Mo et al., 2013). Regarding the human body, the median concentration of DP in serum was three times higher in people from ewaste area (Guiyu Town, $42.6 \mathrm{ng} \mathrm{g}^{-1} \mathrm{lw}$ ) than those from nearby region (Haojiang, $13.7 \mathrm{ng} \mathrm{g}^{-1} \mathrm{lw}$ ). Yan et al. (2012) found that DP levels in serum were significantly higher $(p<0.05)$ in the occupationally exposed workers from the e-waste dismantling region (22$2200 \mathrm{ng} \mathrm{g}^{-1} \mathrm{lw}$ ) than in the urban residents (2.7-91 $\left.\mathrm{ng} \mathrm{g}^{-1} \mathrm{lw}\right)$ in South China. Distinctly high DP levels were also obtained in human hair and indoor dust collected from e-waste dismantling area relative to the control areas (rural and urban) in South China (Zheng et al., 2010). This distribution pattern was consistent with the expected increase in exposure due to dismantling of e-waste (Ren et al., 2009).

\subsection{Urban/industrial activity}

As an additive flame retardant, DP has been widely used in industrial and household products. Therefore, DP may leach from these products and contaminate the surroundings. De la Torre et al. (2011) reported higher levels of DP in sewage sludge from 31 urban Spanish wastewater treatment plants (WWTP), and a significant positive correlation $(\mathrm{r}=$ $0.619, p<0.05$ ) was found between DP concentrations with the contribution of industrial input to waste streams. Zeng et al. (2014) also found relatively higher levels of DP in sewage sludge from the eastern China, especially in coastal areas where the urbanization and industrialization level is higher. In the residential indoor dust in the city of Ottawa, DP levels ranged from 2.3 to $5683 \mathrm{ng} \mathrm{g}^{-1}$, which were comparable to the levels in dust from Stockholm $\left(<0.19-4800 \mathrm{ng} \mathrm{g}^{-1}\right.$ ) (Newton et al., 2015), but were several times higher than those in the sediment of the Great Lakes (Zhu et al., 2007). In the indoor dust from different microenvironments (i.e., home, workplace and car) in the Greater Cairo region, Egypt, both the syn- and anti-isomers were detected in $100 \%$ of the car dust samples reaching 4.94 and $5.65 \mathrm{ng} \mathrm{g}^{-1}$, respectively (Hassan and Shoeib, 2015). In the indoor dust in Beijing, China, the highest DP levels were found in kindergarten dust ( $\left.231 \mathrm{ng} \mathrm{g}^{-1}\right)$, which was even higher than in house dust from Guanzhou, China (mean $18.9 \mathrm{ng} \mathrm{g}^{-1}$ ) (Cao et al., 2014). A regular distribution pattern of DP in dust with particle size was also observed with stronger enrichment on fine particles than coarse particles, implying a potential human exposure to this chemical (Cao et al., 2014). In air, Ren et al. (2008) investigated DP across 97 Chinese urban and rural sites by using PUF disk passive air samplers, and found that DP concentration in urban centers (mean value $15.6 \pm 15.1 \mathrm{pg} \mathrm{m}^{-3}$ ) was approximately 5 times greater than those measured in rural areas $\left(3.5 \pm 5.6 \mathrm{pg} \mathrm{m}^{-3}\right)$. Areas where DP was not detected were primarily limited to rural regions. In the same study, a good correlation was obtained between air DP concentrations and population in urban centers with populations greater than 1 million, which was likely attributable to local sources rather than transboundary influences (Ren et al., 2008). Similar urban-rural distribution of DP in air and plant was also reported in an e-waste area in South China, where DP levels at the e-waste recycling site were at least one order of magnitude higher than those in the reference site (Chen et al., 2011). Salamova and Hites (2013) observed a similar result with significant correlation between DP concentrations in tree bark and human population $(p=0.028)$ when they measured brominated and chlorinated flame retardants including DP in the samples from 12 locations around the globe. Qi et al. (2010) determined DP in surface water and sediment samples from Songhua River in northeastern China. The mean concentration in urban waters of Harbin $\left(0.55 \pm 0.81 \mathrm{ng} \mathrm{L}^{-1}\right)$ was 3 times greater than those measured in the section of Songhua river within the city of Harbin $\left(0.17 \pm 0.38 \mathrm{ng} \mathrm{L}^{-1}\right)$ and more than 15 times greater than in rural area of Songhua River $(0.03 \pm$ $0.07 \mathrm{ng} \mathrm{L}^{-1}$ ). Similar results were also obtained between the sediments from a section of the river within the city of Harbin $\left(0.11 \pm 0.05 \mathrm{ng} \mathrm{g}^{-1}\right.$ $\mathrm{dw})$ and rural area of Songhua River $\left(0.04 \pm 0.05 \mathrm{ng} \mathrm{g}^{-1} \mathrm{dw}\right)$, which suggested the influence of urban activity on environmental DP concentration. In South Korea, Kang et al. (2010) measured DP in fish from 22 river sites around the country, the mean concentrations in the 15 urban sites $\left(36.1 \pm 35.3 \mathrm{ng} \mathrm{g}^{-1} \mathrm{lw}\right.$ ) were approximately 25 times greater than those measured in the rural sites $\left(1.4 \pm 1.0 \mathrm{ng} \mathrm{g}^{-1} \mathrm{lw}\right)$. Significantly different DP levels between rural and urban areas $(p<0.015)$ further suggested that urbanization and industrial activities could be the major emission source of DP rather than LRAT from distant sources (Kang et al., 2010).

\section{General environmental occurrence}

\subsection{Global distribution}

Many studies have revealed occurrence of DP in different matrices since its first detection in the environment in 2006, such as air, water, sediment, wildlife as well as human blood and hair (Fig. 2, Tables S1S7). These global observations indicated that high levels of DP generally occurred in the source areas, such as the North American Great Lakes and Huai'an City in China, e-waste dismantling areas in South China and urban areas in the world as discussed in the previous section. The highest concentrations of DP could be up to several $\mathrm{ng} \mathrm{m}^{-3}$ in ambient air and $\mu \mathrm{g} \mathrm{g}^{-1} \mathrm{dw}$ in soil close to the DP manufacturing facility in Huai'an City (Wang et al., 2010a) and $\mu \mathrm{g} \mathrm{g}^{-1} \mathrm{dw}$ in sediment from an e-waste recycling site in South China (Zhang et al., 2011b). On the other hand, more evidence from all over the world has led to the vision that DP is a worldwide contaminant (Feo et al., 2012; Möller et al., 2010, 2011, 2012a; Sverko et al., 2011a, Vorkamp and Rigét, 2014; Wolschke et al., 2015). As reported by Möller et al. (2010), DP was detected in the marine air boundary layer (sampling at $15 \mathrm{~m}$ above sea level) with concentration ranges from 0.05 to $4.2 \mathrm{pg} \mathrm{m}^{-3}$ in atmosphere and $<$ MDL to $1.3 \mathrm{pg} \mathrm{L}^{-1}$ in seawater from the East Greenland Sea to Antarctica. During the polar expedition cruise from East China Sea to the Arctic, DP was detected at $0.006-0.4 \mathrm{pg} \mathrm{L}^{-1}$ in seawater and 0.01 $1.4 \mathrm{pg} \mathrm{m}^{-3}$ in marine boundary layer air samples (Möller et al., 2011). During another sampling cruise from the East Indian toward the Indian Ocean and further to the Southern Ocean, DP concentrations were observed in the range of $0.26-11 \mathrm{pg} \mathrm{m}^{-3}$ in the air samples (Möller et al., 2012a). These observations revealed a global background level of DP in ocean. The observation in the air samples from Global Atmospheric Passive Sampling (GAPS) indicated that DP could also be detected in some remote areas, especially in the background site at Cape Grim, Tasmania, extremely high level $\left(348 \mathrm{pg} \mathrm{m}^{-3}\right.$ ) was obtained (Sverko et al., 2010a). Relatively higher levels of DP were also detected in the sites in Asia and North America (Sverko et al., 2010a). In tree barks collected around the globe, DP was measured in the range of 0.89-48 $\mathrm{ng} \mathrm{g}^{-1} \mathrm{lw}$ with a relatively high level at a remote site at Bukit Kototabang in Indonesia ( $46 \pm 4 \mathrm{ng} \mathrm{g}^{-1} \mathrm{lw}$ ) (Salamova and Hites, 2013). In contrast to the observation by the GAPS project (Sverko et al., 2010a), DP concentrations in tree bark were the lowest at Cape Grim in Tasmania $\left(0.89 \pm 0.21 \mathrm{ng} \mathrm{g}^{-1} \mathrm{lw}\right)$ (Salamova and Hites, 2013). Although the discrepancy between these two studies cannot be properly explained, the environmental occurrence in background sites suggested a widespread distribution of DP at the global scale.

\subsection{Temporal trends}

To date, results from studies on the temporal distribution of DP were limited to the North American Great Lakes where the first DP manufacturing plant is located. The available data about annual 


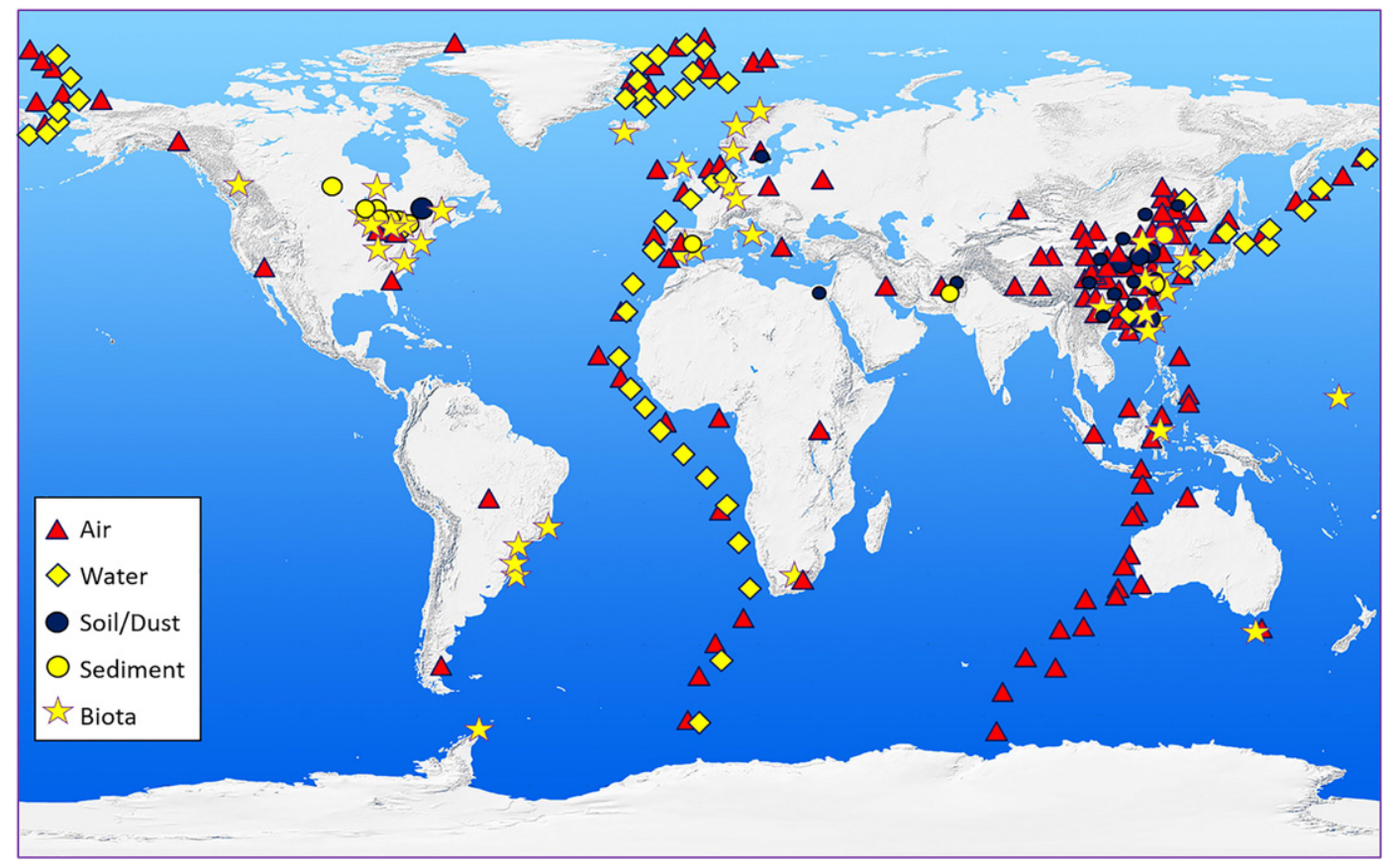

Fig. 2. Global distribution of DP sampling sites. The sampling sites refer to the references in Tables S1-S7.

production amounts varied widely at an estimated range of 4504500 tonnes since 1986 (Qiu et al., 2007). However, DP in ambient air tended to be at a constant level in the Great Lakes region. Results from the Integrated Atmospheric Deposition Network (IADN) sites located in the Great Lakes basin showed that mean concentrations of DP were in the range of $0.23-21.4 \mathrm{pg} \mathrm{m}^{-3}$ over the period of 2003-2007 (Salamova and Hites, 2010), $0.8-20 \mathrm{pg} \mathrm{m}^{-3}$ over the time of 20052006 (Venier and Hites, 2008) and 0.39-23.5 $\mathrm{pg} \mathrm{m}^{-3}$ (sum of the concentrations in vapor phase and particle phase) over the years of 20052009 (Salamova and Hites, 2011). Even though there was a wide range for the means, the DP levels in each site showed a small variation over these sampling periods (Fig. 3). This lack of clear temporal trend suggested that the inputs of DP into the surrounding environment have not distinctly changed during the 2000s (Salamova and Hites, 2011). However, at a longer time scale, DP levels generally declined in sediment and biota collected from the Niagara River and Lake Ontario

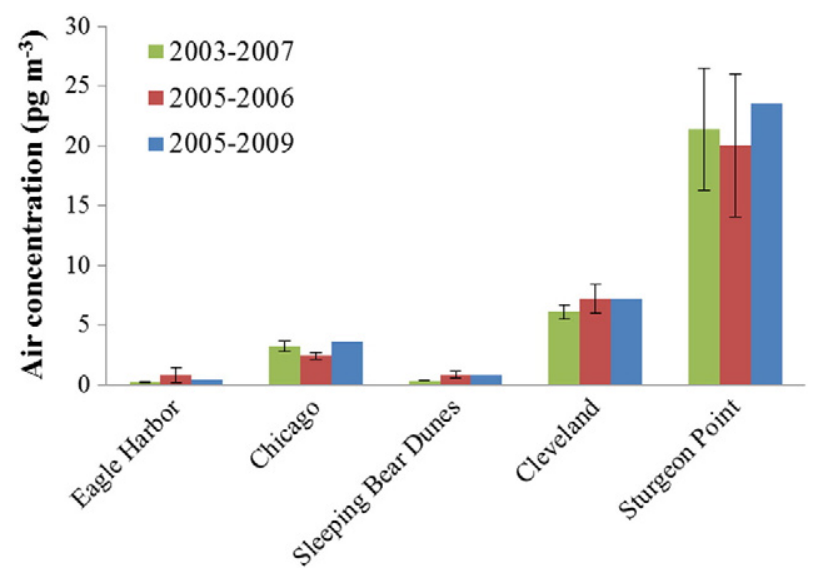

Fig. 3. The variation of DP air concentrations (mean \pm SD) over the period of 2003-2009 in the five sampling sites in the Great Lakes basin. The data was collected from Venier and Hites, 2008, Salamova and Hites, 2010, 2011. since the 1980s (Hoh, et al., 2006; Shen et al., 2010, 2011a; Sverko et al., 2008, 2010b). Some studies indicated a period of increasing levels since the 1970s in sediment from central Lake Ontario, and the levels peaked during 1980-1990s (Qiu et al., 2007; Sverko et al., 2010b; Yang et al., 2011). Although there was a time lag between the peak DP levels among the different studies, DP input to sediment appeared to begin in the 1970s, in agreement with DP production history (Qiu et al., 2007). The peak levels were also observed in Lake Ontario lake trout (Ismail et al., 2009) in 1980s and the eggs of herring gulls (Larus argentatus) from the Laurentian Great Lakes of North America in the mid-1990s (Gauthier and Letcher, 2009). The recent decline tendency of DP levels in sediment and biota could be mainly attributed to the fact that the manufacturing facility in Niagara Falls decreased the production volume and/or improved the control of the discharge (Sverko et al., 2010b; Yang et al., 2011). Although evident impact of the DP plants was observed at the downstream of Niagara River and Lake Ontario, the temporal trend of DP showed some distinctions between the individual lakes of the Great Lakes. Yang et al. (2011) analyzed DP in the sediment cores from all the five lakes. Most sites in Lake Superior and Lake Michigan were still receiving increasing fluxes of DP in recent years, in contrast with the trend in Lake Ontario. Combining with the observation of stronger correlation between the core average synisomer abundance and the distance from the DP manufacturing plant, the authors suspected that LRAT of DP has contributed to the contamination of the Great Lakes. This different pathway from source emission might also be the explanation for the disparity of DP temporal trend among the lakes. The study on temporal trend of DP in other region is scarce. Zhu et al. (2014) found a significant positive temporal shifting trend of the ratio of DP to BDE-209 between 2003 and 2012 in IndoPacific humpback dolphins (Souse chinensis) $(r=0.67, p=0.0005)$ and finless porpoises (Neophocaena phocaenoides) $(r=0.82$, $p<0.0001$ ) from the South China Sea, indicating a use-shift from PBDEs to other alternatives such as DP in China. Whereas, the temporal trend of DP in these biotas was not mentioned (Zhu et al., 2014). A very recent work by Barón et al. (2015) indicated that DP levels in the unborn eggs of three species (black kite, white stork and greater flamingo) from 


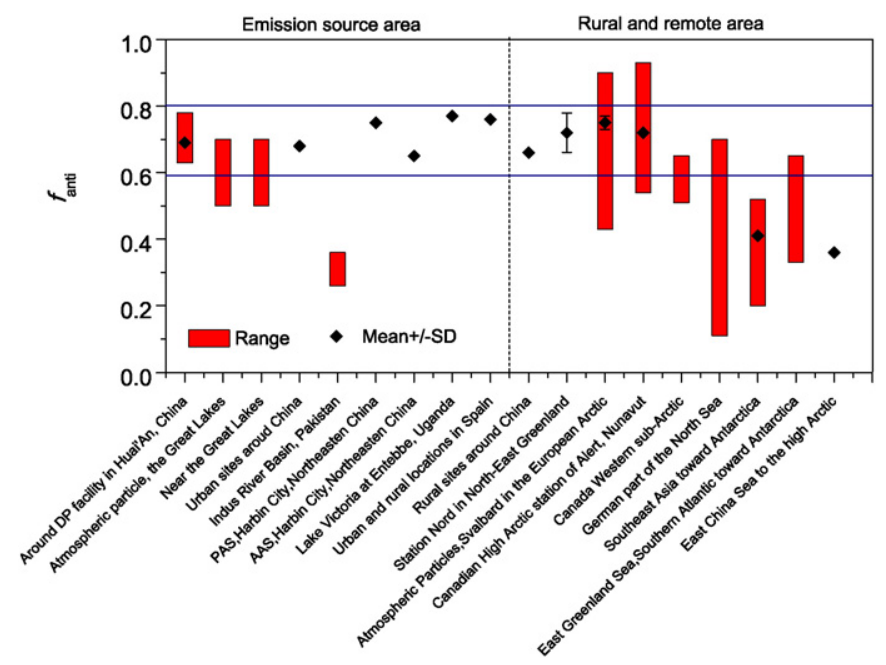

Fig. 4. The distribution of $f_{\text {anti }}$ values in air. The horizontal lines indicate the range of $f_{\text {anti }}$ values in the DP commercial products (0.59-0.80) (the same below). The data was collected from Ali et al., 2015, Arinaitwe et al., 2014, De la Torre et al., 2010b, Hoh et al., 2006, Ma et al., 2011, Möller et al., 2010, 2011, 2012a, 2012b, Ren et al., 2008, Salamova and Hites, 2011, Salamova et al., 2014, Vorkamp et al., 2015, Wang et al., 2010a, Xiao et al., 2012, Yu et al., 2015.

Spain did not change significantly between 1999 (2003 for greater flamingo) and 2011 (2013 for greater flamingo) ( $p>0.05$ ), which was the first study of DP time trends in birds from Europe.

\section{Bioaccumulation and biomagnification potential}

DP was first reported to be detected in archived fish (walleye) from Lake Erie in 2006, which suggested that DP was at least bioavailable (Hoh et al., 2006). Thereafter, different levels of DP were obtained in various biota samples including the human body (Barón et al., 2014a; Gauthier and Letcher, 2009; Guerra et al., 2011; Ren et al., 2009; Salamova and Hites, 2013; Sun et al., 2012; Wu et al., 2010), confirming bioavailability of DP in both the terrestrial and aquatic biotas. Chemicals were considered to be bioaccumulative if the bioaccumulation factor (BAF) was greater than 5000 (Kelly et al., 2007), corresponding to a $\operatorname{logBAF}$ of 3.70. In coastal environment of northern China, biotasediment accumulation factors (BSAF) of DP were determined in the range of 1.0-7.9 with mean value of 4.6 in oyster samples (Jia et al., 2011). In the freshwater food web from a highly contaminated site, South China, the $\operatorname{logBAF}$ values in all the species were higher than 3.70 except Chinese mysterysnail and northern snakehead (Wu et al., 2010), indicating a distinct bioaccumulation of DP in a majority of aquatic species. Besides, a significant biomagnification of syn- and anti-DP was also observed in the present food web, with trophic magnification factors (TMFs) of 11.3 and 6.6, respectively (Wu et al., 2010). In laboratory-based bioaccumulation experiment by Tomy et al. (2008), the biomagnification factors (BMF) were 5.2 for syn-DP and 1.9 for anti-DP on average in Juvenile Rainbow Trout. By contrast, in archived food web samples from Lake Winnipeg and Lake Ontario, trophic level (TL) adjusted biomagnification factors $\left(\mathrm{BMF}_{\mathrm{TL}}\right)$ in the predator-prey relationship indicated interspecies differences in bioaccumulation and biotransformation. $\mathrm{BMF}_{\mathrm{TL}}$ values could reach up to 12 in trout/smelt feeding relationship in Lake Ontario, while in Lake Winnipeg they were calculated as 2.5 and 0.45 for anti- and syn-DP, respectively (Tomy et al., 2007). Lower TMF was also found for DP isomers (2.2 for syn-DP and 1.6 for anti-DP) in the marine food web of Liaodong Bay, North China, where no significant trend was observed for TMF against the trophic level $(p>0.05)$ (Peng et al., 2014). Similar situations were observed in the waterbirds from an e-waste recycling region in South China (Zhang et al., 2011a) and in the unborn eggs of different species from Spain (Barón et al., 2014a), where no significant correlations were obtained between DP levels and trophic levels ( $p>0.05)$, suggesting that the biomagnification of DP was not clear in waterbird and bird egg. By contrast, PBDEs were observed to be evidently biomagnified in waterbirds (Zhang et al., 2011a), bird eggs (Barón et al., 2014a) and the marine food web (Peng et al., 2014). This could be due to the lower $\log K_{O W}$ values of PBDEs (6.0 for BDE-47 and 6.8 for PBDE-99) than those of DP (9.3), and therefore leading to high bioavailability of PBDEs in organisms (Peng et al., 2014).

\section{Isomer ratios of DP in various matrices}

The isomer ratio of DP was commonly used to assess the fate and distribution of DP in the environment and biota. It was represented in the form of either the fractional abundance of anti-DP $\left(f_{\text {anti }}\right)$ in the total DP (anti- + syn-DP), or the fraction of syn-DP $\left(f_{\text {syn }}\right)$ in the total DP. For the purpose of discussion and comparison in this review, all reported $f_{\text {syn }}$ data were converted to $f_{\text {anti }}$.

\subsection{Commercial products}

Commercial DP products consist of about 65\% anti- and 35\% syn-DP resulting in an $f_{\text {anti }}$ value of 0.65 . However, reported $f_{\text {anti }}$ in commercial products were not always consistent because of different production lots and manufacturers (Ren et al., 2008). The $f_{\text {anti }}$ values of commercial DP from both Anpon and OxyChem were reported in the range of 0.590.80 ( $f_{\text {syn }}$ : 0.20-0.41) (Wang et al., 2010a).

\subsection{Atmosphere}

In ambient air, reported $f_{\text {anti }}$ values were generally consistent with those in commercial DP products in emission source areas, while they widely deviated from the commercial values after LRAT. Therefore, the effects of source emission or LRAT could be evidently identified according to DP isomer composition. Most comparable $f_{\text {anti }}$ values in the continental atmosphere could be obtained with those in the technical DP mixture (Fig. 4). For instance, Ren et al.(2008) revealed that the mean $f_{\text {anti }}$ value was $0.67\left(f_{\text {syn }}: 0.33 \pm 0.10\right)$ in air across 97 Chinese urban and rural sites, consistent with the observations in the Great Lakes, North America (Hoh, et al., 2006; Salamova and Hites, 2011), Spain (De la Torre et al., 2010b) and Lake Victoria region, East Africa (Arinaitwe et al., 2014). These results suggested an apparent influence by local emission sources. However, apparent decline of $f_{\text {anti }}$ values could be observed in the marine environment, especially in the locations far away from anthropogenic activities. This could reflect the impact of LRAT on DP isomer composition. Möller et al. (2010) reported that the $f_{\text {anti }}$ value was 0.63 in the English Channel atmosphere, close to the commercial mixture, suggesting Western Europe was a source region of DP in the adjacent coastal waters. The $f_{\text {anti }}$ values then decreased to the range of $0.03-0.72$ with a mean value of $0.33\left(f_{\text {syn }}: 0.67 \pm 0.22\right)$ in the East Greenland Sea. Additionally, the $f_{\text {anti }}$ values significantly decreased with decreasing northern latitude toward an almost constant value of $0.33\left(f_{\text {syn }}: 0.67 \pm 0.03\right)$ southwards of the equator along the Atlantic transect (Möller et al., 2010). These results indicated a higher stability of the syn-isomer toward photodegradation, leading to either a stereoselective depletion of the anti-isomer or isomerization of the anti-isomer to the syn-isomer during atmospheric transport (Möller et al., 2010, 2011, 2012a; Salamova and Hites, 2011). However, no case was available to buttress isomerization of the anti-isomer to the syn-isomer in air to date. As estimated by Fang et al. (2014), syn-DP possibly had a lower $\log K_{O A}$ than that of anti-DP, The $\log K_{O A}$ difference can affect LRAT of DP, which might partly contribute to the decreased $f_{\text {anti }}$ during LRAT (Fang et al., 2014). The decline of $f_{\text {anti }}$ values in the atmosphere with increasing distance from emission source was also found in the terrestrial environment, e.g., the average values were shown as a function of distance from Niagara Falls for the gas, particle, and precipitation phases in the Great Lakes, and a significant negative relationship 


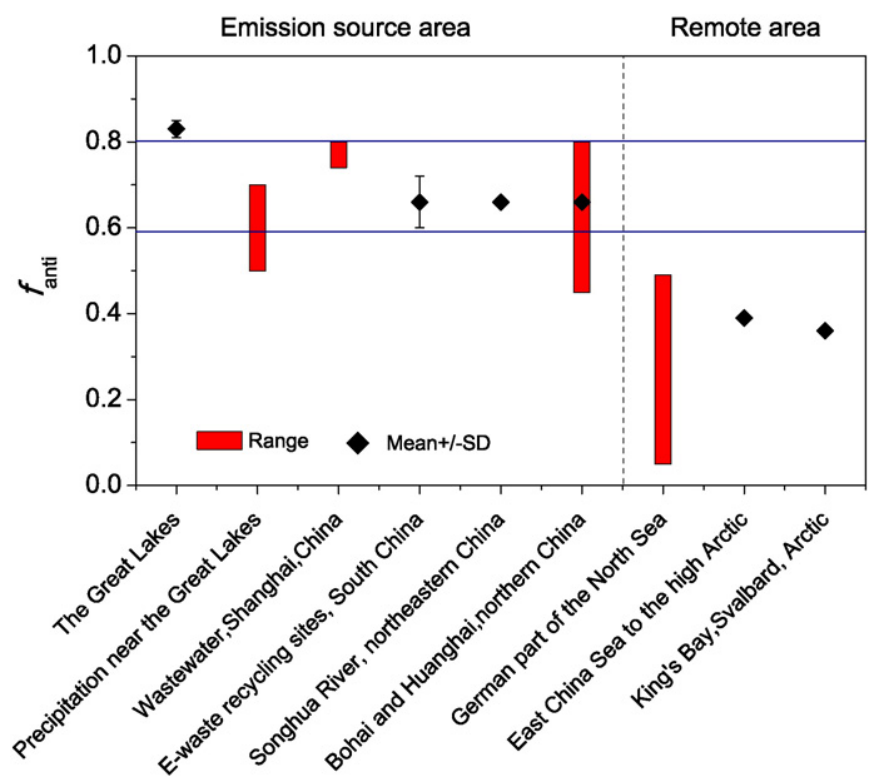

Fig. 5. The distribution of $f_{\text {anti }}$ values in water. The data was collected from Jia et al., 2011, Möller et al., 2011, 2012b, Na et al., 2015, Qi et al., 2010, Salamova and Hites, 2011, Venier et al., 2014, Wu et al., 2010, Xiang et al., 2014.

was obtained in particle phase $\left(r^{2}=0.772, p=0.049\right)$ (Salamova and Hites, 2011). However, it was notable that relatively higher $f_{\text {anti }}$ values were observed in the atmospheric particles from a European Arctic site (Longyearbyen, $f_{\text {anti: }}$ : $0.43-0.90$ with a mean value of $0.75 \pm 0.02$ ) (Salamova et al., 2014), the ambient air at a remote station in the Canadian High Arctic ( $f_{\text {anti: }}$ 0.54-0.93 with a mean value of 0.72 ) (Xiao et al., 2012 ) and sub-Arctic environment in the Yukon Territory (mean $f_{\text {anti }}$ : 0.51-0.61) (Yu et al., 2015). The occurrence of DP in these remote areas was ascribed to the fact that DP was primarily associated with particles and has the LRAT potential (Salamova et al., 2014; Xiao et al., 2012). Whereas, the $f_{\text {anti }}$ values close to the composition of commercial DP mixtures may also suggest an effect of local emission source, although it was not discussed in the previous works (Xiao et al., 2012; Yu et al., 2015).

\subsection{Water}

Limited data indicated the same distribution of DP composition in freshwater and seawater relative to that in atmosphere (Fig. 5). For example, the $f_{\text {anti }}$ values ranged between $0.45-0.80$ (mean value 0.66 ) in seawater along the coast of the northern Chinese sea (Jia et al., 2011), the mean values were $0.66\left(f_{\text {syn }}: 0.34 \pm 0.10\right)$ in Songhua River in northeastern China (Qi et al., 2010) and $0.66 \pm 0.06$ in a reservoir near ewaste recycling workshops in South China (Wu et al., 2010). However, the mean $f_{\text {anti }}$ values in seawater were $0.39\left(f_{\text {syn }}: 0.61 \pm 0.11\right)$ from East China Sea to the Arctic (Möller et al., 2011), $0.47\left(f_{\text {syn }}: 0.53 \pm\right.$ 0.13 ) for East Greenland Sea (Möller et al., 2010) and 0.35 ( $f_{\text {syn }}$ : $0.65 \pm 0.07$ ) along the Atlantic transect (Möller et al., 2010). The sampling sites of these seawaters were far away from the emission source area. The $f_{\text {anti }}$ values were commonly lower than that in the commercial products, but well comparable to the atmospheric distribution. As Salamova and Hites (2011) demonstrated, the $f_{\text {anti }}$ values had a significant decline along the increasing distance from emission source in the particle phase, while this correlation was not significant in precipitation phase. It suggested that the occurrence of DP in the remote oceans was closely related to the atmospheric deposition after its LRAT (Möller et al., 2010).

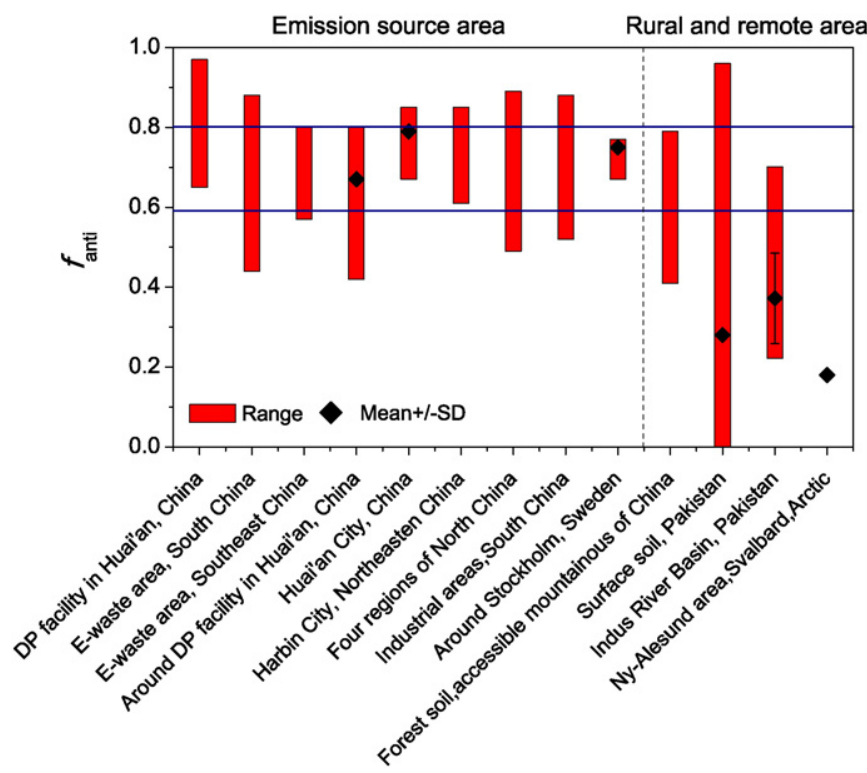

Fig. 6. The distribution of $f_{\text {anti }}$ values in soil. The data was collected from Ali et al., 2015, Ma et al., 2011, 2014, Na et al., 2015, Newton et al., 2015, Syed et al., 2013, Wang et al., 2010a, 2010b, Xiao et al., 2013, Yu et al., 2010, Zhang et al., 2015, Zheng et al., 2015b.

\subsection{Soil, sediment and sewage sludge}

The $f_{\text {anti }}$ values in soil were generally comparable to those in commercial DP products (Fig. 6), especially in source areas. This reflected the direct influence of the emission source. However, relatively higher and lower proportions were also reported in some cases. For example, in Huai'an City of China, the $f_{\text {anti }}$ values varied from 0.65 to 0.97 (mean value 0.79 ) in soils (Wang et al., 2010a), While in North China, the parameter varied greatly with a range of $0.49-0.89$ (Ma et al., 2014). Much lower $f_{\text {anti }}$ values (0.22-0.70, mean 0.37 ) were found in Indus River Basin, Pakistan where a rapid industrialization and urbanization was underway (Ali et al., 2015). The reason behind the lower $f_{\text {anti }}$ ratios was not clear. However, in the sedimentary environment, the $f_{\text {anti }}$ ratios were generally higher than the commercial DP composition from source areas (Fig. 7). For example, the $f_{\text {anti }}$ values were $0.84 \pm 0.01$ in suspended sediments from e-waste recycling areas in South China (Wu et al., 2010), in agreement with the observations in the Great Lakes (Hoh et al., 2006; Sverko et al., 2008; Yang et al., 2011). On the

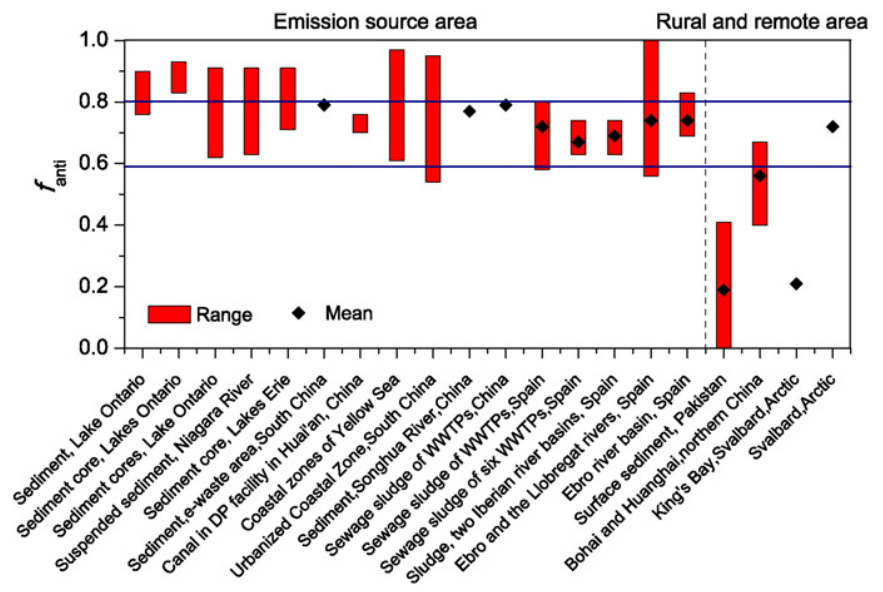

Fig. 7. The distribution of $f_{a n t i}$ values in sediment. The data was collected from Barón et al., 2012, 2014b, De la Torre et al., 2011, Jia et al., 2011, Liu et al., 2014, Ma et al., 2015, Na et al., 2015, Qi et al., 2010, Qiu et al., 2007, Shen et al., 2011a, Syed et al., 2013, Sverko et al., 2008, Wang et al., 2010a, Zeng et al., 2014, Zhang et al., 2011b, Zhao et al., 2011. 
other hand, a regular change of $f_{\text {anti }}$ could be observed in the sediment core from Lake Ontario, where the surficial value of $f_{\text {anti }}$ was 0.76 (on average), and increased to $>0.90$ at the deeper layers (Qiu et al., 2007). A similar trend was observed in one sediment core from Lake Ontario (Yang et al., 2011) and two sediment cores from urbanized coastal zone in South China (Liu et al., 2014). The relatively higher $f_{\text {anti }}$ values and the increased $f_{\text {anti }}$ with the passage of time in sediment were attributed to anti-DP being more persistent in the sedimentary environment (Qiu et al., 2007; Sun et al., 2013; Sverko et al., 2008; Zhao et al., 2011). On the other hand, in marine sediment, the highest $f_{\text {anti }}$ was observed in the fraction with the fine particle size $(<5 \mu \mathrm{m})$, and $f_{\text {anti }}$ was significantly positively correlated with organic carbon content (OC) in the fractionized sediment samples $\left(r^{2}=0.78, p<0.01\right.$ ) (Fang et al., 2014). The enrichment of anti-DP over syn-DP was also attributable to preferential biodegradation of syn-DP in sediment (Fang et al., 2014). This assumption was supported by the observation in sewage sludge from WWTPs in China (Zeng et al., 2014). However, it could not explain the observations in Spanish and North Carolina sewage sludges, where significant syn-DP enrichment was observed during the biological elimination of N and P in WWTPs ( $p<0.05$ ) (De la Torre et al., 2011) and in biosolids (Davis et al., 2012). The discrepancy was also found in Lake Erie sediment cores, where no significant change of $f_{\text {anti }}$ ratios in relation to depth was observed, suggesting no DP stereospecific decomposition related to anaerobic microbial activity (OxyChem, 2007; Sverko et al., 2008). It was plausible that the aqueous solubility of DP isomers may affect their fate in the sedimentary environment. DP is hydrophobic $\left(\log K_{\text {OW }}=9.3, \log K_{P}=6.65\right)$ with solubility of $207 \mathrm{ng} \mathrm{L}^{-1}$ and $572 \mathrm{ng} \mathrm{L}^{-1}$, respectively, for the two isomers (OxyChem, 2007). It suggested syn- and anti-DP possess different physicochemical properties, although no specific information was supplied as to which isomer exhibited which solubility. As estimated through the retention time index in LC columns by Fang et al. (2014), syn-DP was probably more hydrophobic than anti-DP, i.e., higher $\log K_{\text {OW }}$, which could be supported by the simulated experiment with preferentially adsorption of syn-DP by activated charcarbon (ACC). However, the adsorption might be attributable to the larger molecular diameter of anti-DP $(1.42 \mathrm{~nm})$ than that of syn-DP (1.24 nm), which reduced the accessibility of anti-DP to the micropores of ACC (Fang et al., 2014). Therefore, further studies are needed to confirm the hypothesis on the isomer specific biodegradation and adsorption of DP in sediment.

\subsection{Aquatic biota}

The isomer composition of DP in aquatic biota showed a wide variation within and between species (Fig. 8). From the studies in the Great Lakes area and Chinese offshore areas, lower mean $f_{\text {anti }}$ values were generally observed in plankton, invertebrate and fish compared to the commercial DP composition. For instance, $f_{\text {ant } i}$ was $0.44-0.58$ in Lake Ontario lake trout (Shen et al., 2011a), 0.51-0.58 in trout, smelt, alewife and sculpin from Lake Ontario (Tomy et al., 2007), $0.60 \pm 0.05$ in Lake Erie fish (Hoh et al., 2006), 0.34-0.80 (mean 0.55) in oyster, northeast China (Jia et al., 2011). An enrichment of the syn-isomer may be expected since anti-DP is more reactive and susceptible to biological transformation due to that the four $\mathrm{CH}_{2}$-groups of the cyclooctane structure are less shielded by chlorine atoms than those in the syn-isomer (Hoh et al. 2006). The bioaccumulation experiments by Tomy et al. (2008) also indicated that syn-DP showed higher assimilation efficiency and lower depuration rate relative to anti-DP in juvenile rainbow trout (Oncorhynchus mykiss), accounting for the low $f_{\text {anti }}$ values in fish. However, it is not well-known whether this happened in other aquatic species. Fang et al. (2014) calculated the molecular descriptors of anti- and syn-DP using Gaussian 03, the result showed that syn-DP had a higher dipole moment, slightly larger Van der Waals volume, but smaller maximal diameter, which might explain its higher uptake rate in biota (Fang et al., 2014). On the other hand, studies on trophic magnification around the DP facility and e-waste recycling areas showed a wide inter-species variation of $f_{\text {anti }}$ values and a significant negative correlation between these ratios and trophic levels of the aquatic species (Wang et al., 2015; Wu et al., 2010; Zhang et al., 2011a). Similarly, a regression line with negative slope $\left(R^{2}=0.29\right)$ could be obtained based on the data of the entire food web in Lake Ontario, the $f_{\text {anti }}$ values declined from 0.65 in plankton to 0.51 in trout (Tomy et al., 2007). These results were attributed to the fact that species occupying higher trophic levels have lower uptake efficiencies and higher metabolic capacities for the anti-isomer compared to the syn-isomer (Tomy et al., 2007). Some studies on higher aquatic animals, e.g., Chinese sturgeon (Peng et al., 2012), Franciscana dolphin (De la Torre et al., 2012) and ringed seal (Vorkamp et al., 2015), showed relatively higher $f_{a n t i}$ values in various tissues. However, this was observed at relatively low concentrations of DP isomers ( $<\mathrm{ng} \mathrm{g}^{-1}$ lipid weight or wet weight), similar to the finding in kingfishers and their preys in a reference site in the Pearl River Delta

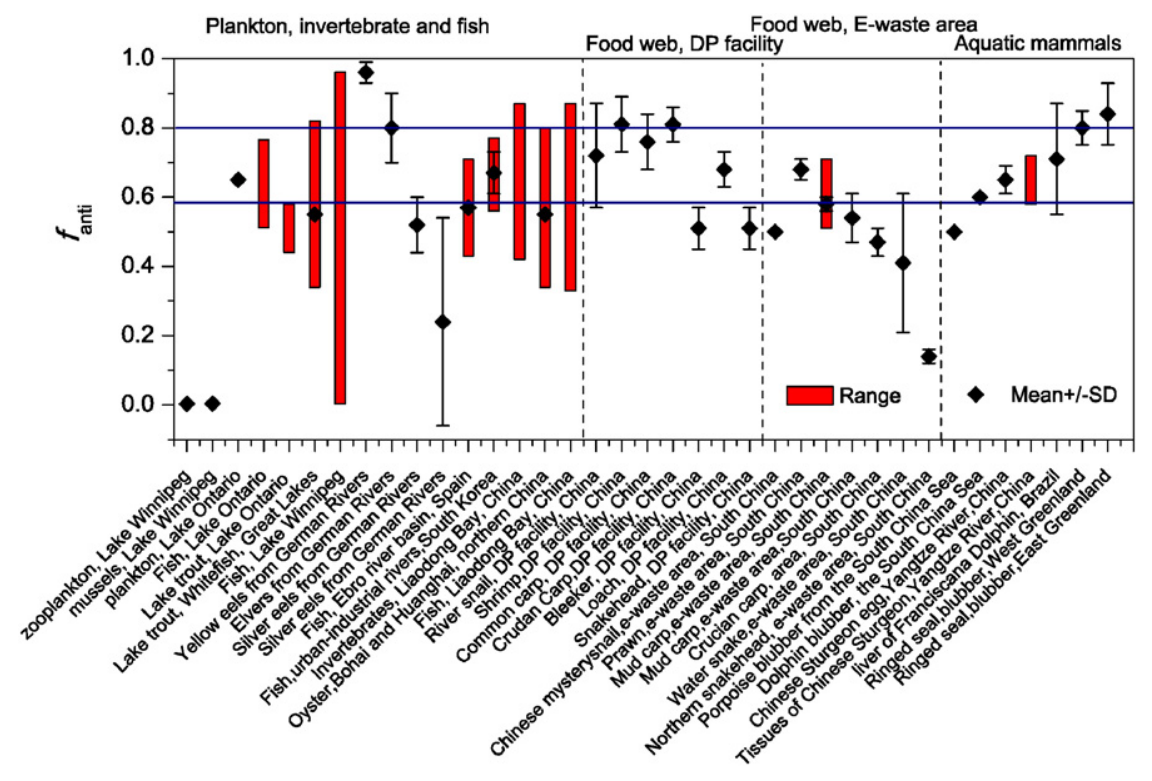

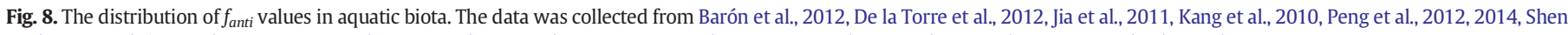
et al., 2010, Sühring et al., 2013, Tomy et al., 2007, Vorkamp et al., 2015, Wang et al., 2015, Wu et al., 2010, Zhang et al., 2011 a, 2011 b, Zhu et al., 2014. 


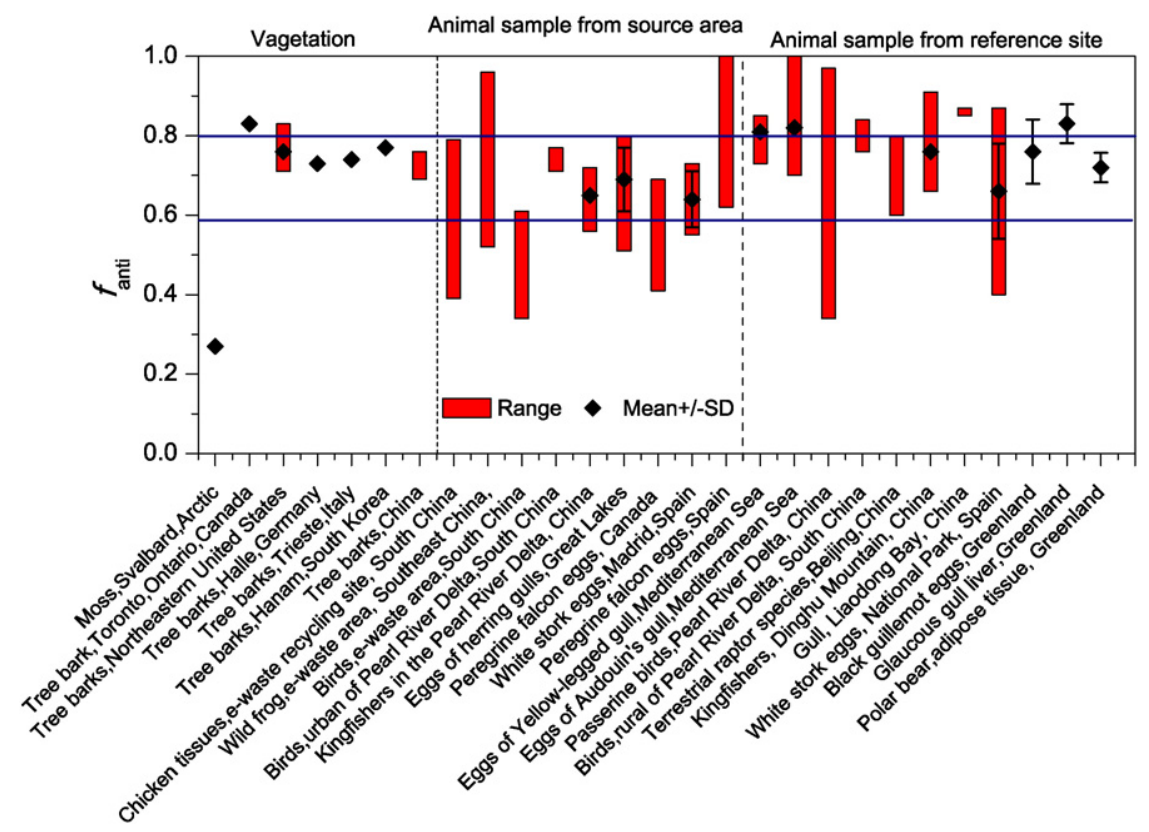

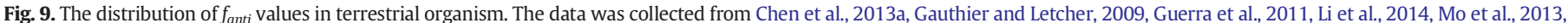

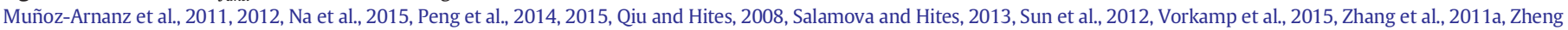
et al., 2014 .

of China (Mo et al., 2013). The higher $f_{\text {anti }}$ values in the aquatic animals were generally associated with lower DP residue levels, whereas it was not clear exactly what causes this relationship.

\subsection{Terrestrial organism}

The $f_{\text {anti }}$ ratios in tree bark were commonly higher but still comparable to that of technical mixture (Fig. 9). While in animals, a disparity of $f_{\text {anti }}$ values could be observed between those from source areas and reference sites. In passerine bird species in South China, the mean $f_{\text {anti }}$ values were in the range of 0.71-0.84, and the values in birds from rural sites were significantly higher than those from urban sites $(p<0.05)$ (Sun et al., 2012). A similar observation on urban-rural difference was also obtained in white stork eggs from Spain $\left(f_{\text {anti }}\right.$ : $0.40-0.87$ ), although no statistical significance was observed between $f_{\text {anti }}$ values from Doñana National Park (mean: $0.66 \pm 0.12$ ) and Madrid (mean: $0.64 \pm 0.07$ ) (Muñoz-Arnanz et al., 2011). Furthermore, $f_{\text {anti }}$ values were significantly higher in the peregrine falcon (Falco peregrinus) eggs from Spain (0.62-1.0) than those from Canada (0.41$0.69)\left(p=0.02\right.$ ) (Guerra et al., 2011). Higher $f_{\text {anti }}$ values were also observed in eggs of two gull species from southwestern Mediterranean Sea $\left(f_{\text {anti: }}\right.$ 0.70-1.0) (Muñoz-Arnanz et al., 2012) compared with those in the herring gull egg pools from the Laurentian Great Lakes of North America (mean $0.69 \pm 0.08$ ) (Gauthier and Letcher, 2009). The higher $f_{\text {anti }}$ values in the terrestrial organisms in reference areas were attributed to the possible alteration of DP (or the already transformed DP) prior

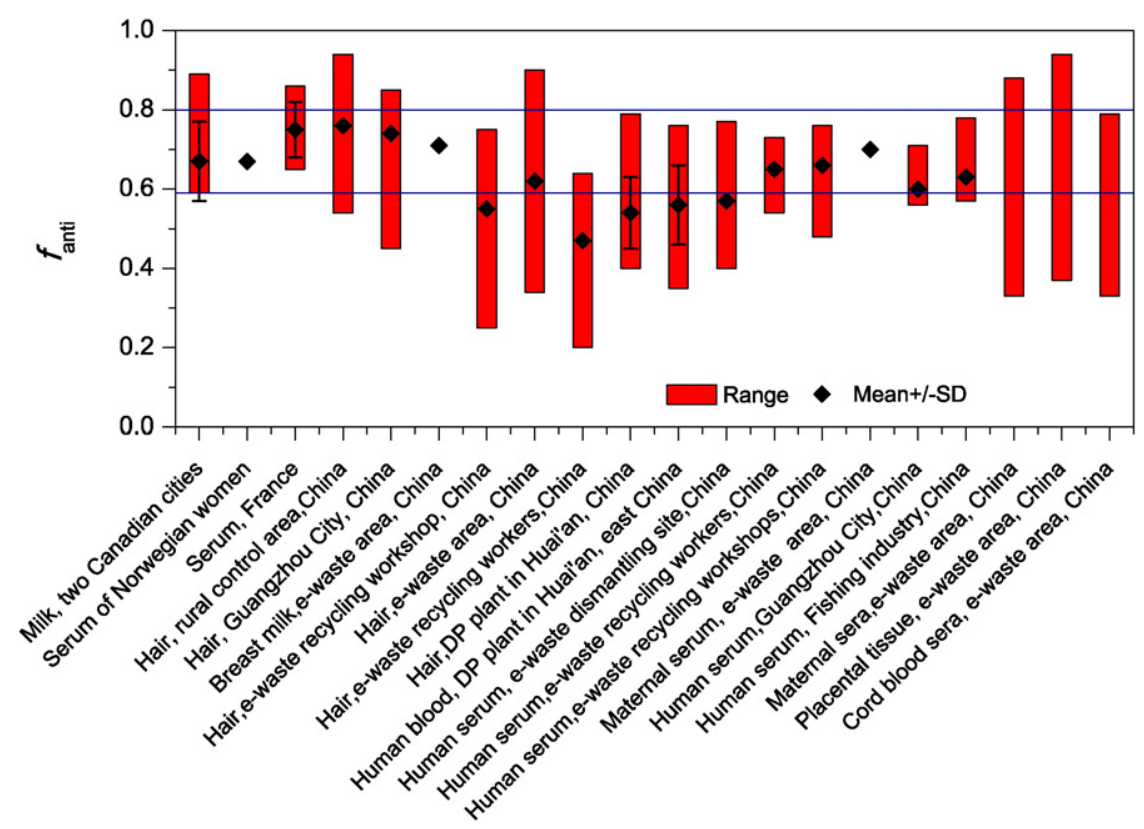

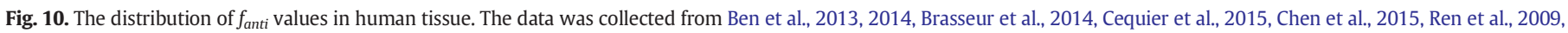
Siddique et al., 2012, Yan et al., 2012, Zhang et al., 2013, Zheng et al., 2010. 
to uptake by the biota since stereoselective enrichment of DP isomers has been observed in environmental matrices (Guerra et al., 2011; Sun et al., 2012). A toxicological study suggested that there was no significant stereoselectivity of DP isomers in the Sprague-Dawley rat tissues in the low DP exposure groups $\left(<1 \mathrm{mg} \mathrm{kg}^{-1} \mathrm{~d}^{-1}\right)\left(f_{\text {anti }}: 0.74-0.78\right)(\mathrm{Li}$ et al., 2013). However, significant reduction of $f_{\text {anti }}$ values (0.26-0.30) was observed in the high DP exposure groups (10-100 $\mathrm{mg} \mathrm{kg}^{-1} \mathrm{~d}^{-1}$ ) and syn-DP was predominant in all tissues (Li et al., 2013). This suggested that species-specific and dose-dependent absorption, deposition, or different excretion of DP isomers could also account for the observed discrepancy of $f_{\text {anti }}$ ratios associated with variation of DP residue levels (Peng et al., 2015).

\subsection{Human beings}

Studies on stereospecificity of DP isomers in human beings showed a generally consistent trend with those in terrestrial organisms (Fig. 10). In the general population from two Canadian cities (Kingston and Sherbrooke) the average $f_{\text {anti }}$ value in human milk was $0.67 \pm 0.10$ (Siddique et al., 2012). In the human serum from France, this value was slightly higher ( $0.75 \pm 0.07$, range: $0.65-0.86$ ) (Brasseur et al., 2014), but still consistent with those in the commercial DP products. However, in the e-waste dismantling regions in South China, the $f_{\text {anti }}$ values ranged from 0.48 to 0.76 (median 0.66 ) in serum of the e-waste recycling workers (Yan et al., 2012), most of the samples tested were slightly lower than the reported commercial $f_{\text {anti }}$ values. Similar results were obtained in serum of the residents ( $f_{\text {anti }}: 0.54-0.73$ with mean 0.65 , Chen et al., 2015; 0.40-0.77 with mean $0.58 \pm 0.11$, Ren et al., 2009) and in hair of e-waste dismantling workers $\left(f_{\text {anti: }}: 0.20-0.64\right.$ with mean 0.47 , Chen et al., 2015; $0.25-0.75$ with mean $0.55 \pm 0.11$, Zheng et al., 2010). DP was speculated to be stereoselected in the environment before entering the body via inhalation, ingestion, or dermal contact (Ren et al., 2009). However, the observation by Chen et al. (2015) revealed that the $f_{\text {anti }}$ values in the hair of e-waste workers $(0.45 \pm$ $0.11)$ were significantly lower than those in dust $(0.54 \pm 0.15)$ and matched serum $(0.64 \pm 0.06)$. The study on occupational exposure to DP also indicated that both the $f_{\text {anti }}$ values in worker's blood (0.350.76 with mean $0.56 \pm 0.10)$ and hair $(0.40-0.79$ with mean $0.54 \pm$ 0.09) were lower than those in the DP products (Zhang et al., 2013) and the surrounding air (0.57-0.79) (Zhang et al., 2015). Considering that these observations generally referred to the human samples from emission source areas, it suggested that syn-DP may be stereoselectively enriched or bioaccumulated relative to anti-DP in the human body in the case of the higher residual level of DP (Zhang et al., 2013, 2015). Stereoselective enrichment of DP in the human body was also supported by the observations on gender difference and tissue distribution. In serum from e-waste recycling workers, the $f_{\text {anti }}$ values $(0.48-0.76)$ were generally lower than those in the commercial products but had a significantly gender difference $(p<0.05)$ (Yan et al., 2012). In human tissues, $f_{\text {anti }}$ values were significantly higher in the placentas relative to the maternal sera or cord sera $(p<0.05)$ (Ben et al., 2014), they were also significantly higher in the maternal sera compared to the cord sera $(p<0.001)$. The significant difference of the $f_{\text {anti }}$ values in three compartments confirmed the occurrence of stereoselective bioaccumulation of DP during the transplacental DP passage (Ben et al., 2014).

\section{DP related compounds and dechlorinated analogs}

\subsection{DP related compounds}

In order to replace Mirex (CAS\# 2385-85-5), a series of highly chlorinated compounds were produced by OxyChem such as Dechlorane (Dec) $602\left(\mathrm{C}_{14} \mathrm{H}_{4} \mathrm{Cl}_{12} \mathrm{O}\right.$, CAS\# 31107-44-5), Dec $603\left(\mathrm{C}_{17} \mathrm{H}_{8} \mathrm{Cl}_{12}\right.$, CAS\# 13560-92-4), Dec $604\left(\mathrm{C}_{13} \mathrm{H}_{4} \mathrm{Br}_{4} \mathrm{Cl}_{6}\right.$, CAS\# 34571-16-9), Chlordene Plus (CP, $\mathrm{C}_{15} \mathrm{H}_{6} \mathrm{Cl}_{12}$, CAS\# 13560-91-3), and DP (Fig. 11). Dec 602 and 604 are on the Nondomestic Substances List published by Environment Canada, indicating possible commercial use of Dec 602 and 604 in Canada currently. The production and actual use of these chemicals are not available. However, these compounds have been globally detected along with DP in various matrices (Tables S8-S12).

In the Great Lakes region, the concentrations of mirex, Dec 602, 603 and 604 were up to several $\mathrm{ng} \mathrm{g}^{-1} \mathrm{dw}$ in sediment (Shen et al., 2010, 2011a, 2011b, 2014; Yang et al., 2011). CP had the lowest overall concentrations, but it was detected in most samples at levels up to $0.27 \mathrm{ng} \mathrm{g}^{-1} \mathrm{dw}$ (Shen et al., 2011b). In Great Lakes fish, the level of mirex could reach up to $4300 \mathrm{ng} \mathrm{g}^{-1} \mathrm{lw}$ (Shen et al., 2011a), while Dec 602, 603, 604 and CP could be detected to some extent with relatively lower concentrations (<LOD (limit of detection) $-180 \mathrm{ng} \mathrm{g}^{-1} \mathrm{lw}$ ) (Shen et al., 2010, 2011a, 2014). Nevertheless, Dec 602 showed greater bioavailable or bioaccumulative than DP in many cases (Barón et al., 2014a, 2015; Guerra et al., 2011; Peng et al., 2014; Shen et al., 2010, 2011a), proposing new concern on its potential ecological risk. The reason might be due to its relatively low $\log K_{O W}$ values (estimated $\log K_{\text {Ow: }}: 8.1$ ) and subsequent high bioavailability compared with DP (estimated value: 11.3) (Shen et al., 2011a). The temporal and spatial distribution of Dechloranes were generally in agreement with those of DP in the Great Lakes, indicating that the OxyChem plant in Niagara Falls was the potential emission source (Shen et al., 2011a; Sverko et al., 2010b; Yang et al., 2011). In addition, analogs of Dec 604 were recently identified in Lake Ontario sediment and fish (Jobst et al., 2013; Shen et al., 2014). These analogs contained fewer bromines and mixed substitutions of bromine and chlorine, such as tribromo-Dec $604\left(\mathrm{Br}_{3}\right.$ Dec 604) analog (known as Dechlorane 604

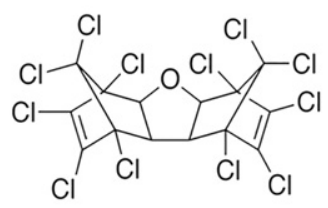

Dec 602<smiles>ClC1=C(Cl)C2(Cl)C3C1C(C1C4C(Cl)=C(Cl)C(Cl)(C13)C4(Cl)Cl)C(Cl)(Cl)C2(Cl)Cl</smiles>

Dec 603

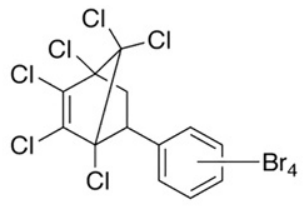

Dec 604
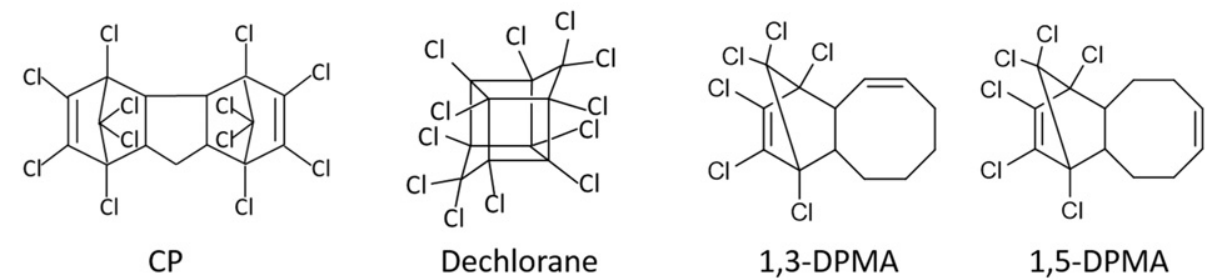

1,5-DPMA

Fig. 11. Molecular structures of Dec 602, Dec 603 Dec 604, CP, Dechlorane, 1,3-DPMA and 1,5-DPMA. 
Component $\mathrm{B}$ (Dec $604 \mathrm{CB}$ )), BrDec604 and $\mathrm{Br}_{2}$ Dec 604 analogs, and mixed $\mathrm{Br}_{2} \mathrm{Cl}_{2}$ Dec 604, $\mathrm{Br}_{3} \mathrm{ClDec} 604, \mathrm{Br}_{2} \mathrm{ClDec} 604$, and $\mathrm{BrCl}_{2}$ Dec 604 analogs. The concentration of Dec 604 CB was even higher than those of Dec 604 in lake trout and whitefish (Shen et al., 2014).

In China, mirex and Dec 602 could be detected in air, soil and sediment around DP plant in Huai'an City (Wang et al., 2010a). However, all the DP related compounds were evidently observed in the aquatic organisms from this area (Wang et al., 2015), the levels of mirex, Dec 602, 603, 604 and CP could reached up to 19,800 $\mathrm{ng} \mathrm{g}^{-1} \mathrm{lw}, 122 \mathrm{ng} \mathrm{g}^{-1} \mathrm{lw}$, $119 \mathrm{ng} \mathrm{g}^{-1} \mathrm{lw}, 329 \mathrm{ng} \mathrm{g}^{-1} \mathrm{lw}$, and $128 \mathrm{ng} \mathrm{g}^{-1} \mathrm{lw}$, respectively, which were much higher than those previous reports in other regions (De la Torre et al., 2012; Guerra et al., 2011; Shen et al., 2010). Mirex and Dec 602 were also observed in soil from 78 of 102 sampling sites around China with a concentration range of $<0.8-230 \mathrm{pg} \mathrm{g}^{-1} \mathrm{dw}$ (Sverko et al., 2011b), while Dec 603 and 604 were not detected. DP analogs have not been manufactured in China except mirex which has been basically eliminated since 2009, and no records are currently available about their use. As indicated by Shen et al. (2011b), CP was found in technical chlordene $(0.05 \pm 0.01 \%)$ and chlordane $(0.76 \pm 0.02 \%$ in the US EPA technical chlordane and $0.65 \pm 0.03 \%$ in those from Restek), Dec 603 was observed in technical aldrin $(0.73 \pm 0.03 \%)$ and dieldrin $(0.31 \pm$ $0.01 \%$ ). In addition, Dec 604 was an impurity (2\%) in a commercial product of mirex. Therefore, the possible source in China could be the impurities or by-product from the manufacturing process of DP or other products such as organic chlorinated pesticides (OCPs) (Shen et al., 2011b; Wang et al., 2015). Related studies in e-waste dismantling areas, which are considered a main emission source of DP, are very limited. Li et al. (2014) reported that the concentrations of mirex and Dec 602 were $0.65-179$ and $0.26-12.4 \mathrm{ng} \mathrm{g}^{-1} \mathrm{lw}$, respectively, in wild frogs (Rana limnocharis) from an e-waste dismantling site in Southeast China, comparable to the DP levels. In other regions of China, Sun et al. (2013) reported that the concentrations of mirex, Dec 602 and 603 ranged from $<$ LOD-0.68 $\mathrm{ng} \mathrm{g}^{-1} \mathrm{dw},<$ LOD-0.048 $\mathrm{ng} \mathrm{g}^{-1} \mathrm{dw}$ and $<$ LOD-0.026 ng g ${ }^{-1} \mathrm{dw}$, respectively in sediments from the Qiantang River in eastern China, while Dec 604 was not detected. Jia et al. (2011) observed low levels of Dec 602 and 603 in marine coastal sediments and oysters from Bohai and Huanghai in northern China. Peng et al. $(2012 ; 2014)$ found a wide distribution of Dec 602, 603 and mirex in sediments and organisms in marine food web of Liaodong Bay and Chinese sturgeon, indicating emission of these compounds into the marine environment.

At the global scale, Möller et al. (2011) observed Dec 602, 603, and 604 in the atmosphere in concentrations of $0.01-0.2 \mathrm{pg} \mathrm{m}^{-3}$, $0.4 \mathrm{pg} \mathrm{m}^{-3}$ and $0.03-0.05 \mathrm{pg} \mathrm{m}^{-3}$, respectively along a polar expedition cruise from East China Sea to the Arctic. Dechloranes were also detected in a few seawater samples with concentrations of $0.2 \mathrm{pg} \mathrm{L}^{-1}, 0.007$ $0.2 \mathrm{pg} \mathrm{L}^{-1}$, and $0.02-0.05 \mathrm{pg} \mathrm{L}^{-1}$, respectively. Recently, Wolschke et al. (2015) reported Dec 602 and 604 in the biotas from the King George Island, Fildes Peninsula, Antarctica, where much higher concentrations of Dec 602 were observed in skua (324-12,400 $\mathrm{pg} \mathrm{g}^{-1} \mathrm{dw}$ ) than those in penguin $\left(<\right.$ LOD-238pg g $\left.{ }^{-1} \mathrm{dw}\right)$ and fish $\left(<\right.$ LOD-4.8 $\mathrm{pg} \mathrm{g}^{-1}$ dw). Moreover, Guerra et al. (2011) reported that mirex, Dec 602, 603 and 604 were significantly higher in peregrine falcon eggs from Canada than Spain $(p \leq 0.005)$, which largely reflected local exposure on the breeding territory, as well as their persistence and bioaccumulation in biota at the top of the food chain. In southeastern and southern coast of Brazil, mirex, Dec 602 and 603 were also detected in Franciscana dolphin (De la Torre et al., 2012). In Spain, mirex and Dec 602 were detected in air in both remote and urban sampling sites and Dec 603 could be detected in some portions (De la Torre et al., 2010b). Furthermore, Dec 602 and 603 were determined in European eel (Anguilla anguilla) samples, where Dec 602 were the dominating FRs in elvers (juvenile eels) (Sühring et al., 2013). DP analogs were also detected in French human serum samples, where Dec 603 was the most abundant Dechloranes (mean value: $2.61 \pm 2.63 \mathrm{ng} \mathrm{g}^{-1} \mathrm{lw}$ ) and followed by $\mathrm{DP}>$ mirex $>$ Dec $602>$ CP (Brasseur et al., 2014). All these studies suggested a worldwide occurrence of DP related compounds and bioavailability of Dechloranes.

Apart from the above norbornene flame retardants, DPMA (CAS\# 135821-04-4), arising from the Diels-Alder reactions of impurities present in feedstock (1,3- or 1,5-cyclooctadiene), were first identified in Great Lakes lake trout (Sverko et al., 2010b). The concentrations (1,3DPMA, approximately $30 \mathrm{ng} \mathrm{g}^{-1} \mathrm{lw}$ ) were approximately 2 orders of magnitude greater than those of DP, suggesting their bioaccumulation potential (Sverko et al., 2010b). This was likely due to its smaller size and lower molecular weight. A similar pattern was also observed in the biota from the King George Island, west Antarctica, where 1,3DPMA was detected with concentrations of $<$ LOD-136 $\mathrm{pg} \mathrm{g}^{-1} \mathrm{dw}$ in skua (Catharacta lonnbergi) (Wolschke et al. 2015). Extremely high levels (1,5-DPMA) were observed in Spanish and Canadian peregrine eggs with concentrations from 1.7 to $469 \mathrm{ng} \mathrm{g}^{-1} \mathrm{lw}$ and 1.2 to $1660 \mathrm{ng} \mathrm{g}^{-1} \mathrm{lw}$, respectively, which was much higher than DP levels (Guerra et al., 2011). Although these observations indicated greater bioavailability of DPMA than DP, DPMA was not found in air, sediment and biota samples in many cases (Barón et al., 2012; De la Torre et al., 2010b; Muñoz-Arnanz et al., 2011; 2012). A recent study in Huai'an, China (close to the DP facility) suggested high levels of DPMA (mean: 13.3$65.5 \mathrm{ng} \mathrm{g}^{-1} \mathrm{lw}$ ) in the fresh water food web, while the ratios of DPMA:DP were very low (0.02-0.44\%) (Wang et al., 2015). The reason was attributed to differences in the source of DP contamination from Spain and Canada. Furthermore, calculated TMF of DPMA was greater than 1 , but not statistically significant ( $p=0.29$ ), suggesting no evident biomagnification in this fresh water food web (Wang et al., 2015). After all, the detection of DPMA was much less than the other DP analogs in the environmental and biota samples. More research work is worth on the environmental risk assessment of these DP related compounds in the future.

\subsection{DP dechlorinated analogs}

DP degradation was first reported by Sverko et al. (2008) in sediments of the lower Great Lakes, where the apparent presence of several mono- and didechlorination products were confirmed. Thereafter, DP dechlorination products were observed in various matrices, including air, dust, sediment and biotas (Tables S8-S12). Two dechlorinated breakdown products of DP were generally reported including undecachloropentacyclooctadecadiene (anti-Cl $\mathrm{Cl}_{11}$-DP) and decachloropentacyclooctadecadiene (anti- $\mathrm{Cl}_{10}-\mathrm{DP}$ ). The concentrations in air, dust and sediment were generally low or even undetectable in most cases, especially for anti-Cl ${ }_{10}$-DP (Chen et al., 2011; Peng et al., 2014; Zeng et al., 2014; Zhao et al., 2011; Zheng et al., 2010). The exception was that relatively higher levels of anti-Cl $\mathrm{Cl}_{11}$-DP were observed in ewaste recycling areas in South China, such as in air (3.68-671 $\mathrm{pg} \mathrm{m}^{-3}$, Chen et al., 2011), indoor dust (nd-20.2 $\mathrm{ng} \mathrm{g}^{-1}$, Zheng et al., 2010) and sediment (6.32-25.0 $\mathrm{ng} \mathrm{g}^{-1} \mathrm{dw}$, Zhang et al., 2011b). Interestingly, anti-Cl $\mathrm{C}_{11}$-DP was observed in air samples at concentrations $<0.1 \mathrm{pg} \mathrm{m}^{-3}$ from East Asia to the Arctic (Möller et al., 2011). anti-Cl $1_{11}$-DP and anti$\mathrm{Cl}_{10}$-DP could also be detected from $<0.001$ to $0.07 \mathrm{pg} \mathrm{L}^{-1}$ in seawater from the Arctic and mainly in the particulate fraction (Möller et al., 2010). The authors suspected that these decomposition products were either formed during LRAT by photodegradation or by biodegradation once DP entered into the ocean (Möller et al., 2010). Although photodegradation of DP was observed in the simulation experiment by Sverko et al. (2008), Raff and Hites (2007) indicated that atmospheric particle bound semivolatile organic compounds (SOCs) might not be photodegradated due to the shielding effect of carbonaceous aerosols on sorbed SOC molecules. However, thermal degradation of DP may occur during e-waste burning processes since the recommended operating temperature of DP is $285^{\circ} \mathrm{C}$, and decomposition may occur at $350{ }^{\circ} \mathrm{C}$ (OxyChem, 2007). Therefore, these two hypotheses are still needed to be confirmed. 
DP dechlorination products were commonly reported in biota including human tissues, the levels were generally much lower than those of DP (Ben et al., 2013; Chen et al., 2011, 2013a; Guerra et al., 2011; Li et al., 2014; Mo et al., 2013; Muñoz-Arnanz, et al., 2011, 2012; Peng et al., 2012, 2014; Sun et al., 2012; Yan et al., 2012; Zhang et al., 2011b; Zheng et al., 2010, 2014). However, an extremely high level was observed in a fresh water food web around DP facility in Huai'an, China, where the concentrations of anti- $\mathrm{Cl}_{10}$-DP and anti- $\mathrm{Cl}_{11^{-}}$ DP was $84.4 \mathrm{ng} \mathrm{g}^{-1} \mathrm{lw}$ and $1030 \mathrm{ng} \mathrm{g}^{-1} \mathrm{lw}$, respectively (Wang et al., 2015).The dechlorinated products of DP in biota were mainly attributed to accumulation from the external habitat environment rather than internal metabolism, although the gender difference observed in some cases suggested that anti- $\mathrm{Cl}_{11}$-DP in the human body may be partly formed from in vivo dechlorination of the anti-isomer (Yan et al., 2012). Tomy et al. (2008) investigated DP metabolites in juvenile rainbow trout and found that even when a high dose was employed in the uptake phase, none of the transformation products including dechlorinated, hydroxylated, methoxylated and methyl sulfone products were detected in the liver extracts. Zheng et al. (2010) found significant correlations and similar slopes of the regression line between anti-Cl ${ }_{11}$-DP and anti-DP in both human hair $(\mathrm{r}=0.865, p<0.0001)$ and indoor dust samples $(r=0.845, p<0.0001)$, suggesting that the dechlorinated products in the human body was likely not from in vivo metabolism but accumulated from environmental matrices through various external exposures. The concentration ratios of anti- $\mathrm{Cl}_{11}$-DP to anti-DP in biotic tissues also provide further evidence. Zhang et al. (2011a,b) observed no significant difference in the ratios of anti- $\mathrm{Cl}_{11^{-}}$ DP to anti-DP between liver and muscle tissues of mud carp, indicating a possible bioaccumulation of anti- $\mathrm{Cl}_{11}$-DP in fish from the external environment. This was mainly based on the assumption that the hepatic metabolism in liver could induce a higher ratio of anti-Cl $\mathrm{Cl}_{11}$-DP to antiDP. A similar result was obtained in wild frogs from an e-waste recycling area in Southeast China (Li et al., 2014). Studies on DP in mother-infant pairs from this area also showed a marginally insignificant difference of anti- $\mathrm{Cl}_{11}$-DP/anti-DP ratios between the maternal sera and placentas (Ben et al., 2014), suggesting that the maternal transfer was the primary source for anti-Cl $\mathrm{Cl}_{11}$-DP in the placental tissues.

\section{Conclusions and recommendations}

The detection of DP in the environment points to its global occurrence. The awareness of its spatial distribution benefits from the rapidly increasing research on the subject in the last decade, while data on its temporal trends are mainly limited to the North American Great Lakes region except for some studies from Spain and China (Barón et al., 2015; Zhu et al., 2014). There seems to be a consensus that DP shows most characteristics of POPs, such as environment persistency, bioaccumulation and LRAT potential. However, its toxicological effects were mainly observed at the transcriptome and metabolome levels (Li et al., 2013; Liang et al., 2014; Wu et al., 2012). More complementary research is warranted to assess its potential for adverse effects on organisms in the future.

The environmental behaviors and fate of the syn- and anti-isomers were well evaluated by the $f_{\text {anti }}$ values. It demonstrated a discrepancy in terms of their environmental persistence, bioaccumulation and biotransformation. The effect of source emission and LRAT could be identified according to DP isomer fraction $\left(f_{a n t i}\right)$ in the environmental matrices. The occurrence of DP in the remote oceans was closely related to the atmospheric deposition after its LRAT. It is most likely that syn-DP is vulnerable to microbial degradation in sediment relative to the antiisomer, resulting in generally higher $f_{a n t i}$ values in sediment. However, the situation is more complex in biota. A higher $f_{\text {anti }}$ ratio was commonly observed associating with lower DP residue levels in both aquatic and terrestrial organisms including the human body, suggesting occurrence of stereoselective processes in vivo apart from stereoselection in the environment prior to entering the body. Despite all that, more studies are still needed to clarify environmental behavior and stereoselective enrichment of DP isomers.

It is worth mentioning that the concentrations of DP and its related compounds have declined in the Great Lakes of North America since the 1990s. However, relatively high levels were reported in the ewaste recycling areas, especially in China. The temporal trend of these contaminants is still unclear. Differently from the DP production status, it is expected that more e-wastes will be generated in the future due to the fast turnover of electronics. Most of these e-wastes end up in the developing countries including China, leading to serious pollution and potential health concerns in the local area since many primitive and improvised recycling activities still exist. Therefore, more attention should be paid to the levels of DP and its analogs in these areas.

To the best of our knowledge, there is no published data available on the toxicological effects of DP analogs except Mirex. Although the levels of DP analogs were in general lower than DP in most cases, their widespread occurrence in the environment and biota necessitates more studies.

\section{Acknowledgement}

This work was jointly funded by National Natural Science Foundation of China (NO. 21477156, 21277165, 21307148, 21321004), Chinese Academy of Sciences (XDB14010100 and YSW2013B01). We greatly thank Prof. Xiaotang Wang from Department of Chemistry and Biochemistry, Florida International University (FIU) for revising this manuscript.

\section{Appendix A. Supplementary data}

Supplementary data to this article can be found online at http://dx. doi.org/10.1016/j.envint.2015.12.026.

\section{References}

Ali, U., Mahmood, A., Syed, J.H., Li, J., Zhang, G., Katsoyiannis, A., Jones, K.C., Malik, R.N., 2015. Assessing the combined influence of TOC and black carbon in soil-air partitioning of PBDEs and DPs from the Indus River Basin, Pakistan. Environ. Pollut. 201, 131-140.

Arinaitwe, K., Muir, D.C., Kiremire, B.T., Fellin, P., Li, H., Teixeira, C., 2014. Polybrominated diphenyl ethers and alternative flame retardants in air and precipitation samples from the northern Lake Victoria region, East Africa. Environ. Sci. Technol. 48 (3), 1458-1466.

Baek, S.Y., Jurng, J., Chang, Y.S., 2013. Spatial distribution of polychlorinated biphenyls, organochlorine pesticides, and dechlorane plus in Northeast Asia. Atmos. Environ. 64, 40-46.

Barón, E., Eljarrat, E., Barceló, D., 2012. Analytical method for the determination of halogenated norbornene flame retardants in environmental and biota matrices by gas chromatography coupled to tandem mass spectrometry. J. Chromatogr. A 1248, 154-160.

Barón, E., Máñez, M., Andreu, A.C., Sergio, F., Hiraldo, F., Eljarrat, E., Barceló, D., 2014a. Bioaccumulation and biomagnification of emerging and classical flame retardants in bird eggs of 14 species from Doñana Natural Space and surrounding areas (South-western Spain). Environ. Int. 68, 118-126.

Barón, E., Santín, G., Eljarrat, E., Barceló, D., 2014b. Occurrence of classic and emerging halogenated flame retardants in sediment and sludge from Ebro and Llobregat river basins (Spain). J. Hazard. Mater. 265, 288-295.

Barón, E., Bosch, C., Máñez, M., Andreu, A., Sergio, F., Hiraldo, F., Eljarrat, E., Barceló, D. 2015. Temporal trends in classical and alternative flame retardants in bird eggs from Doñana Natural Space and surrounding areas (south-western Spain) between 1999 and 2013. Chemosphere 138, 316-323.

Ben, Y.J., Li, X.H., Yang, Y.L., Li, L., Di, J.P., Wang, W.Y., Zhou, R.F., Xiao, K., Zheng, M.Y., Tian, Y., Xu, X.B., 2013. Dechlorane Plus and its dechlorinated analogs from an e-waste recycling center in maternal serum and breast milk of women in Wenling, China. Environ. Pollut. 173, 176-181.

Ben, Y.J., Li, X.H., Yang, Y.L., Li, L., Zheng, M.Y., Wang, W.Y., Xu, X.B., 2014. Placental transfer of Dechlorane Plus in mother-infant pairs in an e-waste recycling area (Wenling, China). Environ. Sci. Technol. 48 (9), 5187-5193.

Brasseur, C., Pirard, C., Scholl, G., De Pauw, E., Viel, J.F., Shen, L., Reiner, E.J., Focant, J.F., 2014. Levels of dechloranes and polybrominated diphenyl ethers (PBDEs) in human serum from France. Environ. Int. 65, 33-40.

Cao, Z., Xu, F., Covaci, A., Wu, M., Wang, H., Yu, G., Wang, B., Deng, S., Huang, J., Wang, X 2014. Distribution patterns of brominated, chlorinated, and phosphorus flame retardants with particle size in indoor and outdoor dust and implications for human exposure. Environ. Sci. Technol. 48 (15), 8839-8846. 
Cequier, E., Marcé, R.M., Becher, G., Thomsen, C., 2015. Comparing human exposure to emerging and legacy flame retardants from the indoor environment and diet with concentrations measured in serum. Environ. Int. 74, 54-59.

Chen, S.J., Tian, M., Wang, J., Shi, T., Luo, Y., Luo, X.J., Mai, B.X., 2011. Dechlorane Plus (DP) in air and plants at an electronic waste (e-waste) site in South China. Environ. Pollut 159 (5), 1290-1296

Chen, D., Wang, Y., Yu, L., Luo, X., Mai, B., Li, S., 2013a. Dechlorane Plus flame retardant in terrestrial raptors from northern China. Environ. Pollut. 176, 80-86.

Chen, S.J., Feng, A.H., He, M.J., Chen, M.Y., Luo, X.J., Mai, B.X., 2013b. Current levels and composition profiles of PBDEs and alternative flame retardants in surface sediments from the Pearl River Delta, southern China: comparison with historical data. Sci. Total Environ. 444, 205-211.

Chen, K., Zheng, J., Yan, X., Yu, L., Luo, X., Peng, X., Yu, Y., Yang, Z., Mai, B., 2015. Dechlorane Plus in paired hair and serum samples from e-waste workers: correlation and differences. Chemosphere 123, 43-47.

Davis, E.F., Klosterhaus, S.L., Stapleton, H.M., 2012. Measurement of flame retardants and triclosan in municipal sewage sludge and biosolids. Environ. Int. 40, 1-7.

De la Torre, A., Concejero, M., Sverko, E., Shen, L., Martinez, M., Reiner, E., Alaee, M., 2010a. Effect of source temperature on the ECNI/MS spectra of Dechlorane Plus isomers. Organohalogen Compd. 72, 1737-1740.

De la Torre, A., Pacepavicius, G., Shen, L., Reiner, E., Jimenez, B., Alaee, M., Martinez, M. 2010b. A. Dechlorane Plus and related compounds in Spanish air. Organohalogen Compd. 72, 929-932.

De la Torre, A., Sverko, E., Alaee, M., Martinez, M.A., 2011. Concentrations and sources of Dechlorane Plus in sewage sludge. Chemosphere 82 (5), 692-697.

De la Torre, A., Alonso, M.A., Martinez, M.A., Sanz, P., Shen, L., Reiner, E.J., Lailson-Brito, J. Torres, J.P., Bertozzi, C., Marigo, J., Barbosa, L., Cremer, M., Secchi, E., Malm, O., Eljarrat E., Barcelo, D., 2012. Dechloranes and related compounds in franciscana dolphin (Pontoporia blainvillei) from southeastern and southern coast of Brazil. Environ. Sci. Technol. 46 (22), 12364-12372.

Fang, M., Kim, J.C., Chang, Y.S., 2014. Investigating Dechlorane Plus (DP) distribution and isomer specific adsorption behavior in size fractionated marine sediments. Sci. Total Environ. 481, 114-120.

Feo, M.L., Baron, E., Eljarrat, E., Barcelo, D., 2012. Dechlorane Plus and related compound in aquatic and terrestrial biota: a review. Anal. Bioanal. Chem. 404 (9), 2625-2637.

Gauthier, L.T., Letcher, R.J., 2009. Isomers of Dechlorane Plus flame retardant in the eggs of herring gulls (Larus argentatus) from the Laurentian Great Lakes of North America: temporal changes and spatial distribution. Chemosphere 75 (1), 115-120.

Guerra, P., Fernie, K., Jimenez, B., Pacepavicius, G., Shen, L., Reiner, E., Eljarrat, E., Barcelo, D., Alaee, M., 2011. Dechlorane Plus and related compounds in peregrine falcon (Falco peregrinus) eggs from Canada and Spain. Environ. Sci. Technol. 45 (4), 1284-1290.

Hassan, Y., Shoeib, T., 2015. Levels of polybrominated diphenyl ethers and novel flame retardants in microenvironment dust from Egypt: an assessment of human exposure. Sci. Total Environ. 505, 47-55.

Hoh, E., Zhu, L.Y., Hites, R.A., 2006. Dechlorane plus, a chlorinated flame retardant, in the Great Lakes. Environ Sci Technol 40 (4), 1184-1199.

Huber, S., Warner, N.A., Nygård, T., Remberger, M., Harju, M., Uggerud, H.T., Kaj, L., Hanssen, L., 2015. A broad cocktail of environmental pollutants found in eggs of three seabird species from remote colonies in Norway. Environ. Toxicol. Chem. 34 (6), 1296-1308

Ismail, N., Gewurtz, S.B., Pleskach, K., Whittle, D.M., Helm, P.A., Marvin, C.H., Tomy, G.T. 2009. Brominated and chlorinated flame retardants in Lake Ontario, Canada, lake trout (Salvelinus namaycush) between 1979 and 2004 and possible influences of food-web changes. Environ. Toxicol. Chem. 28 (5), 910-920.

Jia, H.L., Sun, Y.Q., Liu, X.J., Yang, M., Wang, D.G., Qi, H., Shen, L., Sverko, E., Reiner, E.J., Li, Y.F., 2011. Concentration and bioaccumulation of dechlorane compounds in coastal environment of northern China. Environ. Sci. Technol. 45 (7), 2613-2618.

Jobst, K.J., Shen, L., Reiner, E.J., Taguchi, V.Y., Helm, P.A., McCrindle, R., Backus, S., 2013. The use of mass defect plots for the identification of (novel) halogenated contaminants in the environment. Anal. Bioanal. Chem. 405 (10), 3289-3297.

Kang, J.H., Kim, J.C., Jin, G.Z., Park, H., Baek, S.Y., Chang, Y.S., 2010. Detection of Dechlorane Plus in fish from urban-industrial rivers. Chemosphere 79 (8), 850-854.

Kelly, B.C., Ikonomou, M.G., Blair, J.D., Morin, A.E., Gobas, F.A.P.C., 2007. Food web-specific biomagnification of persistent organic pollutants. Science 317, 236-239.

Klánová, J., Eupr, P., Kohoutek, J., Harner, T., 2008. Assessing the influence of meteorological parameters on the performance of polyurethane foam-based passive air samplers. Environ. Sci. Technol. 42 (2), 550-555.

Li, L., Wang, W., Lv, Q., Ben, Y., Li, X., 2014. Bioavailability and tissue distribution of Dechloranes in wild frogs (Rana limnocharis) from an e-waste recycling area in Southeast China. J. Environ. Sci. (China) 26 (3), 636-642.

Li, Y., Yu, L.H., Wang, J.S., Wu, J.P., Mai, B.X., Dai, J.Y., 2013. Accumulation pattern of Dechlorane Plus and associated biological effects on rats after $90 \mathrm{~d}$ of exposure. Chemosphere 90 (7), 2149-2156

Liang, X., Li, W., Martyniuk, C.J., Zha, J., Wang, Z., Cheng, G., Giesy, J.P., 2014. Effects of Dechlorane Plus on the hepatic proteome of juvenile Chinese sturgeon (Acipenser sinensis). Aquat. Toxicol. 148, 83-91.

Liu, H.H., Hu, Y.J., Luo, P., Bao, L.., Qiu, J.W., Leung, K.M., Zeng, E.Y., 2014. Occurrence of halogenated flame retardants in sediment off an urbanized coastal zone: association with urbanization and industrialization. Environ. Sci. Technol. 48 (15), 8465-8473.

Luo, X.J., Wu, J.P., Chen, S.J., Mai, B.X., 2013. Species-specific bioaccumulation of polybrominated diphenyl ethers, hexabromocyclododecan and dechlorane plus in biota: a review. Sci. China Chem. 43 (3), 291-304.

Ma, J., Qiu, X., Liu, D., Zhao, Y., Yang, Q., Fang, D., 2014. Dechlorane Plus in surface soil of North China: levels, isomer profiles, and spatial distribution. Environ. Sci. Pollut Res. Int. 21 (14), 8870-8877.
Ma, W.L., Liu, L.Y., Hong, Q.A., Sun, D.Z., Shen, J.M., Wang, D.G., Li, Y.F., 2011. Dechlorane plus in multimedia in northeastern Chinese urban region. Environ. Int. 37 (1), 66-70. Ma, Y., Xie, Z.Y., Halsall, C., Möller, A., Yang, H., Zhong, G., Cai, M., Ebinghaus, R., 2015. The spatial distribution of organochlorine pesticides and halogenated flame retardants in the surface sediments of an Arctic fjord: the influence of ocean currents vs. glacial runoff. Chemosphere 119, 953-960

Möller, A., Xie, Z.Y., Sturm, R., Ebinghaus, R., 2010. Large-scale distribution of Dechlorane Plus in air and seawater from the Arctic to Antarctica. Environ. Sci. Technol. 44 (23), 8977-8982.

Möller, A., Xie, Z.Y., Cai, M., Zhong, G., Huang, P., Cai, M., Sturm, R., He, J., Ebinghaus, R., 2011. Polybrominated diphenyl ethers vs alternate brominated flame retardants and Dechloranes from East Asia to the Arctic. Environ. Sci. Technol. 45 (16), 6793-6799.

Möller, A., Xie, Z., Cai, M., Sturm, R., Ebinghaus, R., 2012a. Brominated flame retardants and Dechlorane Plus in the marine atmosphere from Southeast Asia toward Antarctica. Environ. Sci. Technol. 46 (6), 3141-3148.

Möller, A., Xie, Z., Caba, A., Sturm, R., Ebinghaus, R., 2012b. Occurrence and air-seawater exchange of brominated flame retardants and Dechlorane Plus in the North Sea. Atmos. Environ. 46, 346-353.

Mo, L., Wu, J.P., Luo, X.J., Sun, Y.X., Zheng, X.B., Zhang, Q., Zou, F.S., Mai, B.X., 2013. Dechlorane Plus flame retardant in kingfishers (Alcedo atthis) from an electronic waste recycling site and a reference site, South China: influence of residue levels on the isomeric composition. Environ. Pollut. 174, 57-62.

Muñoz-Arnanz, J., Saez, M., Hiraldo, F., Baos, R., Pacepavicius, G., Alaee, M., Jimenez, B., 2011. Dechlorane plus and possible degradation products in white stork eggs from Spain. Environ. Int. 37 (7), 1164-1168.

Muñoz-Arnanz, J., Roscales, J.L., Vicente, A., Aguirre, J.I., Jiménez, B., 2012. Dechlorane Plus in eggs of two gull species (Larus michahellis and Larus audouinii) from the southwestern Mediterranean Sea. Anal. Bioanal. Chem. 404 (9), 2765-2773.

Na, G., Wei, W., Zhou, S., Gao, H., Ma, X., Qiu, L., Ge, L., Bao, C., Yao, Z., 2015. Distribution characteristics and indicator significance of dechloranes in multi-matrices at NyÅlesund in the Arctic. J. Environ. Sci. (China) 28, 8-13.

Newton, S., Sellström, U., de Wit, C.A., 2015. Emerging flame retardants, PBDEs, and HBCDDs in indoor and outdoor media in Stockholm, Sweden. Environ. Sci. Technol. 49 (5), 2912-2920.

Qi, H., Liu, L.Y., Jia, H.L., Li, Y.F., Ren, N.Q., You, H., Shi, X.Y., Fan, L.L., Ding, Y.S., 2010. Dechlorane Plus in surficial water and sediment in a northeastern Chinese river. Environ. Sci. Technol. 44 (7), 2305-2308.

OxyChem, 2007. Dechlorane Plus manual. (http://www.oxy.com/OurBusinesses/ Chemicals/Products/Documents/dechloraneplus/dechlorane_plus.pdf. (Accessed Jun 2015))

Peng, H., Zhang, K., Wan, Y., Hu, J., 2012. Tissue distribution, maternal transfer, and agerelated accumulation of dechloranes in Chinese sturgeon. Environ. Sci. Technol. 46 (18), 9907-9913.

Peng, H., Wan, Y., Zhang, K., Sun, J.X., Hu, J.Y., 2014. Trophic transfer of Dechloranes in the marine food web of Liaodong Bay, North China. Environ. Sci. Technol. 48, 5458-5466.

Peng, Y., Wu, J.P., Tao, L., Mo, L., Zheng, X.B., Tang, B., Luo, X.J., Mai, B.X., 2015. Accumulation of Dechlorane Plus flame retardant in terrestrial passerines from a nature reserve in South China: the influences of biological and chemical variables. Sci. Total Environ. $514,77-82$.

Peverly, A.A., Ma, Y., Venier, M., Rodenburg, Z., Spak, S.N., Hornbuckle, K.C., Hites, R.A., 2015. Variations of flame retardant, polycyclic aromatic hydrocarbon, and pesticide concentrations in Chicago's atmosphere measured using passive sampling. Environ. Sci. Technol. 49 (9), 5371-5379.

Qiu, X.H., Marvin, C.H., Hites, R.A., 2007. Dechlorane plus and other flame retardants in a sediment core from Lake Ontario. Environ. Sci. Technol. 41 (17), 6014-6019.

Qiu, X.H., Hites, R.A., 2008. Dechlorane plus and other flame retardants in tree bark from the Northeastern United States. Environ. Sci. Technol. 42 (1), 31-36.

Raff, J.D., Hites, R.A., 2007. Deposition versus photochemical removal of PBDEs from Lake Superior air. Environ. Sci. Technol. 41, 6725-6731.

Ren, N.Q., Sverko, E., Li, Y.F., Zhang, Z., Harner, T., Wang, D.G., Wan, X.N., Mccarry, B.E., 2008. Levels and isomer profiles of Dechlorane Plus in Chinese air. Environ. Sci. Technol. 42 (17), 6476-6480.

Ren, G.F., Yu, Z.Q., Ma, S.T., Li, H.R., Peng, P.G., Sheng, G.Y., Fu, J.M., 2009. Determination of Dechlorane Plus in serum from electronics dismantling workers in South China. Environ Sci Technol 43 (24), 9453-9457.

Salamova, A., Hites, R.A., 2010. Evaluation of tree bark as a passive atmospheric sampler for flame retardants, PCBs, and organochlorine pesticides. Environ. Sci. Technol. 44 (16), 6196-6201

Salamova, A., Hites, R.A., 2011. Dechlorane plus in the atmosphere and precipitation near the Great Lakes. Environ. Sci. Technol 45 (23), 9924-9930.

Salamova, A., Hites, R.A., 2013. Brominated and chlorinated flame retardants in tree bark from around the Globe. Environ. Sci. Technol. 47 (1), 349-354.

Salamova, A., Hermanson, M.H., Hites, R.A., 2014. Organophosphate and halogenated flame retardants in atmospheric particles from a European Arctic site. Environ. Sci. Technol. 48 (11), 6133-6140.

Shen, L., Reiner, E.J., Macpherson, K.A., Kolic, T.M., Sverko, E., Helm, P.A., Bhavsar, S.P., Brindle, I.D., Marvin, C.H., 2010. Identification and screening analysis of halogenated norbornene flame retardants in the Laurentian Great Lakes: Dechloranes 602, 603, and 604. Environ Sci Technol 44 (2), 760-766.

Shen, L., Reiner, E.J., Helm, P.A., Marvin, C.H., Hill, B., Zhang, X.M., Macpherson, K.A., Kolic, T.M., Tomy, G.T., Brindle, I.D., 2011a. Historic trends of Dechloranes 602, 603, 604, Dechlorane Plus and other norbornene derivatives and their bioaccumulation potential in Lake Ontario. Environ. Sci. Technol. 45 (8), 3333-3340.

Shen, L., Reiner, E.J., MacPherson, K.A., Kolic, T.M., Helm, P.A., Richman, L.A., Marvin, C.H. Burniston, D.A., Hill, B., Brindle, I.D., McCrindle, R., Chittim, B.G., 2011b. Dechloranes 
602, 603, 604, Dechlorane Plus, and Chlordene Plus, a newly detected analogue, in tributary sediments of the Laurentian Great Lakes. Environ. Sci. Technol. 45 (2), 693-699.

Shen, L., Jobst, K.J., Reiner, E.J., Helm, P.A., McCrindle, R., Taguchi, V.Y., Marvin, C.H., Backus, S., MacPherson, K.A., Brindle, I.D., 2014. Identification and occurrence of analogues of Dechlorane 604 in Lake Ontario sediment and their accumulation in fish. Environ. Sci. Technol. 48 (19), 11170-11177.

Shoeib, M., Harner, T., 2002. Characterization and comparison of three passive air samplers for persistent organic pollutants. Environ. Sci. Technol. 36 (19), 4142-4151.

Siddique, S., Xian, Q.M., Abdelouahab, N., Takser, L., Phillips, S.P., Feng, Y.L., Wang, B., Zhu, J.P., 2012. Levels of dechlorane plus and polybrominated diphenylethers in human milk in two Canadian cities. Environ. Int. 39 (1), 50-55.

Sühring, R., Möller, A., Freese, M., Pohlmann, J.D., Wolschke, H., Sturm, R., Xie, Z., Hanel, R., Ebinghaus, R., 2013. Brominated flame retardants and dechloranes in eels from German Rivers. Chemosphere 90 (1), 118-124.

Sun, Y., Luo, X., Wu, J., Mo, L., Chen, S., Zhang, Q., Zou, F., Mai, B., 2012. Species- and tissuespecific accumulation of Dechlorane Plus in three terrestrial passerine bird species from the Pearl River Delta, South China. Chemosphere 89 (4), 445-451.

Sun, J., Zhang, A., Fang, L., Wang, J., Liu, W., 2013. Levels and distribution of Dechlorane Plus and related compounds in surficial sediments of the Qiantang River in eastern China: the results of urbanization and tide. Sci. Total Environ. 443, 194-199.

Sverko, E., Tomy, G.T., Marvin, C.H., Zaruk, D., Reiner, E., Helm, P.A., Hill, B., Mccarry, B.E., 2008. Dechlorane plus levels in sediment of the lower Great Lakes. Environ. Sci. Technol. 42 (2), 361-366.

Sverko, E., Harner, T., Lee, S.C., Mccarry, B.E., 2010a. Dechlorane Plus in the Global Atmospheric Passive Sampling (GAPS) Study Organohalogen Compd.

Sverko, E., Reiner, E.J., Tomy, G.T., McCrindle, R., Shen, L., Arsenault, G., Zaruk, D., MacPherson, K.A., Marvin, C.H., Helm, P.A., McCarry, B.E., 2010b. Compounds structurally related to Dechlorane Plus in sediment and biota from Lake Ontario (Canada). Environ. Sci. Technol. 44 (2), 574-579.

Sverko, E., Tomy, G.T., Reiner, E.J., Li, Y.F., McCarry, B.E., Arnot, J.A., Law, R.J., Hites, R.A., 2011a. Dechlorane Plus and related compounds in the environment: a review. Environ. Sci. Technol. 45 (12), 5088-5098.

Sverko, E., Reiner, E.J., Kannan, K., 2011b. Dechloranes in surface soil and air in China. The 6th National Symposium on Persistent Organic Pollutants (China POPs Forum 2011) (in Chinese).

Syed, J.H., Malik, R.N., Li, J., Wang, Y., Xu, Y., Zhang, G., Jones, K.C., 2013. Levels, profile and distribution of Dechloran Plus (DP) and polybrominated diphenyl ethers (PBDEs) in the environment of Pakistan. Chemosphere 93 (8), 1646-1653.

Tomy, G.T., Pleskach, K., Ismail, N., Whittle, D.M., Helm, P.A., Sverko, E., Zaruk, D., Marvin, C.H., 2007. Isomers of dechlorane plus in Lake Winnipeg and Lake Ontario food webs. Environ. Sci. Technol. 41 (7), 2249-2254.

Tomy, G.T., Thomas, C.R., Zidane, T.M., Murison, K.E., Pleskach, K., Hare, J., Arsenault, G., Marvin, C.H., Sverko, E., 2008. Examination of isomer specific bioaccumulation parameters and potential in vivo hepatic metabolites of syn- and anti-Dechlorane Plus isomers in juvenile rainbow trout (Oncorhynchus mykiss). Environ. Sci. Technol. 42 (15), 5562-5567.

Venier, M., Hites, R.A., 2008. Flame retardants in the atmosphere near the Great Lakes. Environ. Sci. Technol. 42 (13), 4745-4751.

Venier, M., Dove, A., Romanak, K., Backus, S., Hites, R., 2014. Flame retardants and legacy chemicals in Great Lakes' water. Environ. Sci. Technol. 48 (16), 9563-9572.

Wolschke, H., Meng, X.Z., Xie, Z., Ebinghaus, R., Cai, M., 2015. Novel flame retardants (NFRs), polybrominated diphenyl ethers (PBDEs) and dioxin-like polychlorinated biphenyls (DL-PCBs) in fish, penguin, and skua from King George Island, Antarctica. Mar. Pollut. Bull. 96 (1-2), 513-518.

Vorkamp, K., Rigét, F.F., 2014. A review of new and current-use contaminants in the Arctic environment: evidence of long-range transport and indications of bioaccumulation. Chemosphere 111, 379-395.

Vorkamp, K., Bossi, R., Rigét, F.F., Skov, H., Sonne, C., Dietz, R., 2015. Novel brominated flame retardants and dechlorane plus in Greenland air and biota. Environ. Pollut. 196, 284-291.

Wang, D.G., Yang, M., Qi, H., Sverko, E., Ma, W.L., Li, Y.F., Alaee, M., Reiner, E.J., Shen, L., 2010a. An Asia-specific source of Dechlorane Plus: concentration, isomer profiles, and other related compounds. Environ. Sci. Technol. 44 (17), 6608-6613.

Wang, B., Iino, F., Huang, J., Lu, Y., Yu, G., Morita, M., 2010b. Dechlorane Plus pollution and inventory in soil of Huai'an City, China. Chemosphere 80 (11), 1285-1290.

Wang, D.G., Guo, M.X., Pei, W., Byer, J.D., Wang, Z., 2015. Trophic magnification of chlorinated flame retardants and their dechlorinated analogs in a fresh water food web. Chemosphere 118, 293-300.

Wu, J.P., Zhang, Y., Luo, X.J., Wang, J., Chen, S.J., Guan, Y.T., Mai, B.X., 2010. Isomer-specific bioaccumulation and trophic transfer of Dechlorane Plus in the freshwater food web from a highly contaminated site, South China. Environ. Sci. Technol. 44 (2), 606-611.
Wu, B., Liu, S., Guo, X.C., Zhang, Y., Zhang, X.X., Li, M., Cheng, S.P., 2012. Responses of mouse liver to Dechlorane Plus exposure by integrative transcriptomic and metabonomic studies. Environ. Sci. Technol. 46 (19), 10758-10764.

Xian, Q., Siddique, S., Li, T., Feng, Y.L., Takser, L., Zhu, J., 2011. Sources and environmental behavior of dechlorane plus - a review. Environ. Int. 37 (7), 1273-1284.

Xiang, N., Chen, L., Meng, X.Z., Li, Y.L., Liu, Z., Wu, B., Dai, L., Dai, X., 2014. Polybrominated diphenyl ethers (PBDEs) and dechlorane plus (DP) in a conventional wastewater treatment plant (WWTP) in Shanghai: seasonal variations and potential sources. Sci. Total Environ. 487, 342-349.

Xiao, H., Shen, L., Su, Y., Barresi, E., Dejong, M., Hung, H., Lei, Y.D., Wania, F., Reiner, E.J. Sverko, E., Kang, S.C., 2012. Atmospheric concentrations of halogenated flame retardants at two remote locations: the Canadian High Arctic and the Tibetan Plateau. Environ. Pollut. 161, 154-161.

Xiao, K., Wang, P., Zhang, H., Shang, H., Li, Y., Li, X., Ren, D., Chen, W., Zhang, Q., 2013. Levels and profiles of Dechlorane Plus in a major e-waste dismantling area in China. Environ. Geochem. Health 35 (5), 625-631.

Yan, X., Zheng, J., Chen, K.H., Yang, J., Luo, X.J., Yu, L.H., Chen, S.J., Mai, B.X., Yang, Z.Y., 2012 Dechlorane Plus in serum from e-waste recycling workers: influence of gender and potential isomer-specific metabolism. Environ. Int. 49, 31-37.

Yang, R., Wei, H., Guo, J., McLeod, C., Li, A., Sturchio, N.C., 2011. Historically and currently used dechloranes in the sediments of the Great Lakes. Environ. Sci. Technol. 45 (12) 5156-5163.

Yu, Z.Q., Lu, S.Y., Gao, S.T., Wang, J.Z., Li, H.R., Zeng, X.Y., Sheng, G.Y., Fu, J.M., 2010. Levels and isomer profiles of Dechlorane Plus in the surface soils from e-waste recycling areas and industrial areas in South China. Environ. Pollut. 158 (9), 2920-2925.

Yu, Y., Hung, H., Alexandrou, N., Roach, P., Nordin, K., 2015. Multi-year measurements of flame retardants and organochlorine pesticides in air in Canada's Western sub-Arctic. Environ. Sci. Technol. 49 (14), 8623-8630.

Zeng, L., Yang, R., Zhang, Q., Zhang, H., Xiao, K., Zhang, H., Wang, Y., Lam, P.K., Jiang, G. 2014. Current levels and composition profiles of emerging halogenated flame retardants and dehalogenated products in sewage sludge from municipal wastewater treatment plants in China. Environ. Sci. Technol. 48 (21), 12586-12594.

Zhang, X.L., Luo, X.J., Liu, H.Y., Yu, L.H., Chen, S.J., Mai, B.X., 2011a. Bioaccumulation of several brominated flame retardants and dechlorane plus in waterbirds from an e-waste recycling region in South China: associated with trophic level and diet sources. Environ. Sci. Technol. 45 (2), 400-405

Zhang, Y., Wu, J.P., Luo, X.J., Wang, J., Chen, S.J., Mai, B.X., 2011b. Tissue distribution of Dechlorane Plus and its dechlorinated analogs in contaminated fish: high affinity to the brain for anti-DP. Environ. Pollut. 159 (12), 3647-3652.

Zhang, H., Wang, P., Li, Y., Shang, H., Wang, Y., Wang, T., Zhang, Q., Jiang, G., 2013. Assessment on the occupational exposure of manufacturing workers to Dechlorane Plus through blood and hair analysis. Environ. Sci. Technol. 47 (18), 10567-10573.

Zhang, Q.H., Zhu, C.F., Zhang, H.D., Wang, P., Li, Y.M., Ren, D.W., Jiang, G.B., 2015. Concentrations and distributions of Dechlorane Plus in environmental samples around a Dechlorane Plus manufacturing plant in East China. Sci. Bull. 60 (8), 792-797.

Zhao, Z., Zhong, G., Möller, A., Xie, Z., Sturm, R., Ebinghaus, R., Tang, J., Zhang, G., 2011. Levels and distribution of Dechlorane Plus in coastal sediments of the Yellow Sea, North China. Chemosphere 83 (7), 984-990.

Zheng, J., Wang, J., Luo, X.J., Tian, M., He, L.Y., Yuan, J.G., Mai, B.X., Yang, Z.Y., 2010 Dechlorane Plus in human hair from an e-waste recycling area in South China: comparison with dust. Environ. Sci. Technol. 44 (24), 9298-9303.

Zheng, X., Luo, X., Zhang, Y., Wu, J., Mai, B., 2014. Sources, gastrointestinal absorption and stereo-selective and tissue-specific accumulation of Dechlorane Plus (DP) in chicken. Chemosphere 114, 241-246.

Zheng, X., Xu, F., Chen, K., Zeng, Y., Luo, X., Chen, S., Mai, B., Covaci, A., 2015a. Flame retardants and organochlorines in indoor dust from several e-waste recycling sites in South China: composition variations and implications for human exposure. Environ. Int. 78, 1-7.

Zheng, Q., Nizzetto, L., Li, J., Mulder, M.D., Sáňka, O., Lammel, G., Bing, H., Liu, X., Jiang, Y., Luo, C., Zhang, G., 2015b. Spatial distribution of old and emerging flame retardants in Chinese forest soils: sources, trends and processes. Environ. Sci. Technol. 49 (5), 2904-2911.

Zhu, J., Feng, Y.L., Shoeib, M., 2007. Detection of Dechlorane Plus in residential indoor dust in the city of Ottawa, Canada. Environ. Sci. Technol. 41, 7694-7698.

Zhu, B., Lam, J.C., Yang, S., Lam, P.K., 2013. Conventional and emerging halogenated flame retardants (HFRs) in sediment of Yangtze River Delta (YRD) region, East China. Chemosphere 93 (3), 555-560.

Zhu, B., Lai, N.L., Wai, T.C., Chan, L.L., Lam, J.C., Lam, P.K., 2014. Changes of accumulation profiles from PBDEs to brominated and chlorinated alternatives in marine mammals from the South China Sea. Environ. Int. 66, 65-70. 